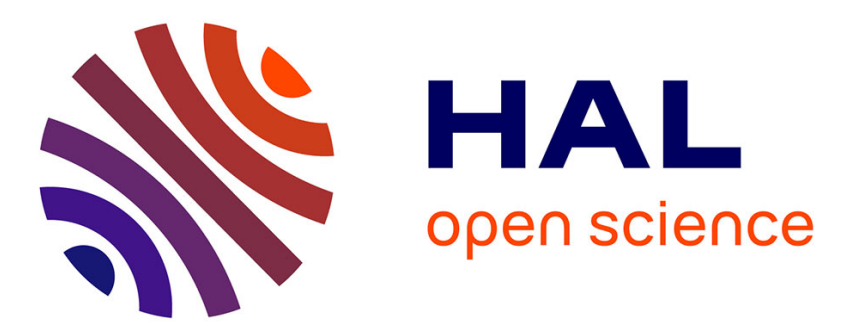

\title{
A refined sinus plate finite element for laminated and sandwich structures under mechanical and thermomechanical loads
}

\author{
P. Vidal, O. Polit
}

\section{- To cite this version:}

P. Vidal, O. Polit. A refined sinus plate finite element for laminated and sandwich structures under mechanical and thermomechanical loads. Computer Methods in Applied Mechanics and Engineering, 2013, 253, pp.396-412. 10.1016/j.cma.2012.10.002 . hal-01366914

HAL Id: hal-01366914

https://hal.science/hal-01366914

Submitted on 8 Jan 2018

HAL is a multi-disciplinary open access archive for the deposit and dissemination of scientific research documents, whether they are published or not. The documents may come from teaching and research institutions in France or abroad, or from public or private research centers.
L'archive ouverte pluridisciplinaire HAL, est destinée au dépôt et à la diffusion de documents scientifiques de niveau recherche, publiés ou non, émanant des établissements d'enseignement et de recherche français ou étrangers, des laboratoires publics ou privés. 


\title{
A refined sinus plate finite element for laminated and sandwich structures under mechanical and thermomechanical loads
}

\author{
P. Vidal *, O. Polit \\ LEME, EA 4416, Université Paris Ouest, 50 rue de Sèvres, 92410 Ville d'Avray, France
}

\begin{abstract}
A B S T R A C T
This paper presents a $C^{1} 6$-node triangular finite element for multilayered composite plates submitted to mechanical and thermomechanical loads. It is based on the sinus model with layer refinement and includes the transverse normal effect. This kinematics allows to exactly ensure both (i) the continuity conditions for displacements and transverse shear stresses at the interfaces between layers of a laminated structure, and (ii) the boundary conditions at the upper and lower surfaces of the plates. It is important to notice that the number of unknowns is independent of the number of layers. This finite element is able to model both thin and very thick plates without any pathologies of the classic plate finite elements (shear locking, spurious modes, etc.). It is built on the Argyris interpolation for bending and the Ganev interpolation for membrane displacements and transverse shear rotations. The representation of the transverse shear strains by cosine functions allows avoiding shear correction factors. In addition, the transverse normal stress can be accurately recovered from equilibrium equations at the post-processing level, using the high degree of interpolation polynomia.

Both mechanical and thermomechanical tests for thin and very thick plates are presented in order to evaluate the capability of this new finite element to give accurate results with respect to exact threedimensional solutions. Both convergence velocity and accuracy are discussed and this new finite element yields very satisfactory results at a low computational cost. In particular, the transverse shear stresses computed from the constitutive relation are well estimated with regards to other equivalent single layer or even with respect to layerwise models.
\end{abstract}

\section{Introduction}

Composite and sandwich structures are widely used in the industrial field due to their excellent mechanical properties, especially their high specific stiffness and strength. In this context, they can be subjected to severe mechanical and thermal loading (through heating or cooling). For composite design, accurate knowledge of displacements and stresses is required. So, it is important to take into account effects of the transverse shear deformation due to the low ratio of transverse shear modulus to axial modulus, or failure due to delamination, etc. In fact, they can play an important role on the behavior of structures in services, which leads to evaluate precisely their influence on local stress fields in each layer, particularly at the interface between layers.

The aim of this paper is to develop a triangular finite element (FE) with high capabilities and good numerical properties dedicated to the modeling of composite structures. In particular, this

\footnotetext{
* Corresponding author.

E-mail address: philippe.vidal@u-paris10.fr (P. Vidal).
}

2D approach must be suitable to give 3D stresses for very thick to thin structures submitted to mechanical and thermal loading.

Research is active on the development of new theoretical models for heterogeneous structures and multifield problems. Two families of models can be identified:

- The equivalent single layer models (ESLM), where the classical Love-Kirchhoff (CLT) and Reissner-Mindlin (FSDT) models can be found for plates. The first one leads to inaccurate results for composites because both transverse and normal strains are neglected. The second one needs a shear correction factor. So, the higher order shear deformation theory has been developed (see the work of Reddy [1]), but transverse shear and normal stress continuity conditions at the interfaces between layers are often violated. In the ESLM context, a simple way to improve the estimation of the mechanical quantities has been proposed by Murakami [2]: one function is added in each in-plane displacement to introduce the slope discontinuity at the interface between two adjacent layers. It allows to describe the so-called zig-zag effect. 
- The layer-wise models (LWM) that aim at overcoming the restriction of the ESL concerning the discontinuity of out-ofplane stresses at the interface between adjacent layers. The reader can refer to the works of Pagano [3] and Reddy [4].

According to Reddy [5], the number of unknowns remains independent of the number of constitutive layers in the ESLM, while the same set of variables is used in each layer for the LWM.

Another way for obtaining new models is based on the introduction of interface conditions into higher-order model pertaining to the ESLM or to the LWM. This permits to reduce the number of unknowns and can be viewed as a Zig-Zag model. Excellent reviews have been made in the following articles [6-9] or in the most recent review proposed by Zhang and Yang [10].

Furthermore, research is also active on the development of new FE and, with respect to our study, triangular plate FE of the literature shall be next briefly described. We only focus on the FE based on higher-order theories. In Gaudenzi et al. [11] and Chaudhuri and Seide [12], three-node FE based on a layerwise approach are presented, but the computational cost increases with the number of layers.

In the ESL approach, some authors do not use the interface continuity conditions on transverse stresses and we can cite among other: Raghuram et al. [13] have presented a $C^{1}$ three-node FE introducing only the top and bottom free conditions on the transverse shear stresses. The evaluation is about free-edge effects and this FE is not free of Poisson locking as a linear expansion is used for the transverse displacement; Sheikh and Chakrabarti [14] have developed a non-conforming six-node FE based on the Reddy's theory. The free conditions on the transverse shear stresses at the top and bottom surface of the plate are fulfilled but the transverse normal stress is neglected; Das et al. [15] have also developed a $\mathrm{C}^{0}$ three-node FE based on the $\{3,2\}$ order single-layer theory but the evaluations are dedicated to sandwich structures; Thai et al. [16] have built a $C^{0}$ three-node $\mathrm{FE}$ without transverse normal stress. All these FE need post-processing calculations to improve the transverse shear stresses distributions.

The interface continuity conditions have been introduced by some authors: Di Sciuva [17] has proposed a three-node FE based on a third-order theory without transverse normal stress, and this FE exhibits a severe transverse shear locking; Oh and Cho [18] have presented a non-conforming three-node FE based on a cubic zigzag plate theory but need a post-processsing treatment to recover accurate transverse shear and normal stresses. It must be noted that the thermo-electric-mechanical coupling is addressed in this contribution. Zhen and Wanji [19] have proposed a three-node FE satisfying the $\mathrm{C}^{1}$ weak-continuity conditions at the inter-element and some results of this contribution will be used in the section dedicated to numerical assessment for further comparison.

In this paper, a new six-node triangular finite element is described and applied to rectangular laminated and sandwich plate analysis. Based on the Sinus theory developed in Vidal and Polit [20] for beams, its generalization to plate is presented here for the first time. This work can also be viewed as an evolution of a previous triangular FE by Polit and Touratier [21] towards three directions: (i) modeling of thin to very thick structures, (ii) modeling of any lamination schemes and (iii) capability in multifield problems. As in the beam theory, the double superposition hypothesis is introduced for the in-plane displacement. The transverse displacement is refined allowing the use of the three-dimensional constitutive law. This is essential for thick structures and multifield problems. All interface continuity and boundary conditions are exactly satisfied for displacement and transverse shear stresses using the Heaviside function. This function allows to take into account any lamination scheme, whereas the FE presented in [21] was dedicated to cross ply and symmetric angle ply schemes. Moreover, transverse shear stresses can be obtained directly from the threedimensional constitutive law. The original Sinus plate theory uses only five unknown functions as FSDT while this new theory requires six more functions, thus involving eleven independent generalized displacements. In order to develop a conform, efficient and accurate FE, Argyris and Ganev interpolations are used as in Polit and Touratier [21]. These FE approximations are $C^{1}$ and semi- $C^{1}$, respectively, providing a high convergence rate. Furthermore, since Argyris interpolation is a polynomial of the fifth-order and Ganev interpolation of the fourth-order, the field compatibility for the FE approximations of the transverse shear strains is automatically fulfilled, avoiding the transverse shear locking.

This new triangular FE with eleven unknown functions is detailed out in the first two sections. Numerical evaluations are subsequently presented. After a preliminary convergence analysis, laminated (two and three layers) and sandwich plates under mechanical loading are discussed and, finally, two and three layered plates submitted to thermal loads are addressed. In these numerical evaluations, displacement and stress results of this new FE are compared with three-dimensional elasticity solutions of Pagano [22] for mechanical loads and of Bhaskar et al. [23] for thermal loads. Present results are also assessed against solutions obtained from classical models (CLT, FSDT) and original Sinus theory using the same FE approximations, as well as against other models previously published in open literature.

\section{Description of the plate problem}

\subsection{The governing equations for mechanics}

Let us consider a plate occupying the domain $\mathcal{V}=\Omega \times\left[-\frac{h}{2} \leqslant z \leqslant \frac{h}{2}\right]$ in a Cartesian coordinate $\left(x_{1}, x_{2}, z\right)$. The plate is defined by an arbitrary region $\Omega$ in the $\left(x_{1}, x_{2}\right)$ plane, as midplane for $z=0$, and by a constant thickness $h$, see Fig. 1 .

\subsubsection{Constitutive relation}

The plate is assumed to be made of NC perfectly bonded orthotropic layers. Using matrix notation, the three dimensional constitutive law of the $k$ th layer is given by:

$$
\begin{aligned}
& {\left[\begin{array}{c}
\sigma_{11}^{(k)} \\
\sigma_{22}^{(k)} \\
\sigma_{33}^{(k)} \\
\sigma_{23}^{(k)} \\
\sigma_{13}^{(k)} \\
\sigma_{12}^{(k)}
\end{array}\right]=} {\left[\begin{array}{cccccc}
C_{11}^{(k)} & C_{12}^{(k)} & C_{13}^{(k)} & 0 & 0 & C_{16}^{(k)} \\
& C_{22}^{(k)} & C_{23}^{(k)} & 0 & 0 & C_{26}^{(k)} \\
& & C_{33}^{(k)} & 0 & 0 & C_{36}^{(k)} \\
& & & C_{44}^{(k)} & C_{45}^{(k)} & 0 \\
& s y m & & C_{55}^{(k)} & 0 \\
& & & & C_{66}^{(k)}
\end{array}\right]\left[\begin{array}{c}
\varepsilon_{11}^{(k)} \\
\varepsilon_{22}^{(k)} \\
\varepsilon_{33}^{(k)} \\
\gamma_{23}^{(k)} \\
\gamma_{13}^{(k)} \\
\gamma_{12}^{(k)}
\end{array}\right] } \\
& \text { i.e. }\left[\sigma^{(k)}\right]=\left[C^{(k)}\right]\left[\varepsilon^{(k)}\right],
\end{aligned}
$$

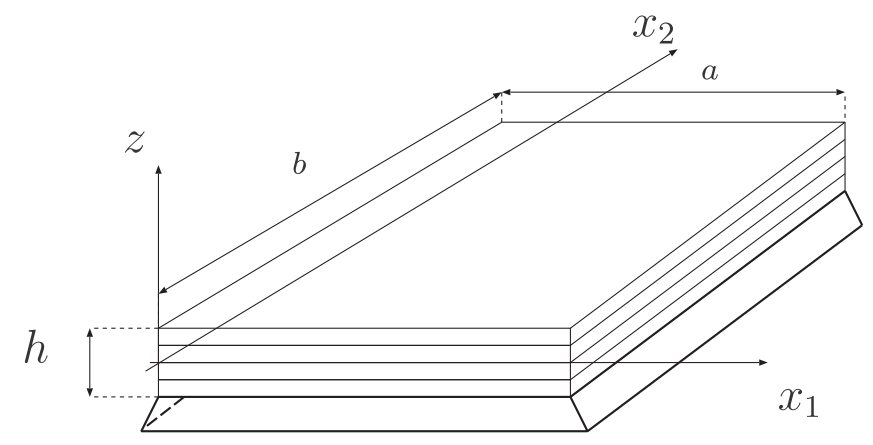

Fig. 1. The laminated plate and coordinate system. 
where we denote the stress vector $[\sigma]$, the strain vector $[\varepsilon]$ and $C_{i j}$ the three-dimensional stiffness coefficients.

For the thermomecanical analysis, the three-dimensional constitutive law is modified introducing the thermal expansion coefficients $\alpha_{i}^{(k)}$ and the variation of the temperature $\Delta T$, as follows:

$$
\left[\begin{array}{l}
\sigma_{11}^{(k)} \\
\sigma_{22}^{(k)} \\
\sigma_{33}^{(k)}
\end{array}\right]=\left[\begin{array}{lll}
C_{11}^{(k)} & C_{12}^{(k)} & C_{13}^{(k)} \\
& C_{22}^{(k)} & C_{23}^{(k)} \\
s y m & & C_{33}^{(k)}
\end{array}\right]\left[\begin{array}{c}
\varepsilon_{11}^{(k)}-\alpha_{1}^{(k)} \Delta T \\
\varepsilon_{22}^{(k)}-\alpha_{2}^{(k)} \Delta T \\
\varepsilon_{33}^{(k)}-\alpha_{3}^{(k)} \Delta T
\end{array}\right] .
$$

\subsubsection{The weak form of the boundary value problem}

Using the above matrix notation and for admissible virtual displacement $\vec{u}^{*} \in U^{*}$, the variational principle reads:

Find $\vec{u} \in U$ (space of admissible displacements) such that

$$
-\int_{\mathcal{V}}\left[\varepsilon\left(\vec{u}^{*}\right)\right]^{T}[\sigma(\vec{u})] d \mathcal{V}+\int_{\mathcal{V}}\left[u^{*}\right]^{T}[f] d \mathcal{V}+\int_{\partial \mathcal{V}_{F}}\left[u^{*}\right]^{T}[F] d \partial \mathcal{V}
$$$$
=0 \quad \forall \vec{u}^{*} \in U^{*},
$$

where $[f]$ and $[F]$ are the prescribed body and surface forces applied on $\partial \mathcal{V}_{F}$ and $\varepsilon\left(\vec{u}^{*}\right)$ is the virtual strain. $U^{*}$ is the space of admissible virtual displacements.

\subsection{The displacement field for laminated plates}

Based on the sinus function (see $[24,25]$ ), a model which takes into account the transverse normal deformation is presented in this section. It is based on

- various works on beams, plates and shells, $[24,26,27,42]$ covering the refined theory, and

- the so-called 1, 2-3 double-superposition theory of Li and Liu [28], developed in the sinus approach for beams in Vidal and Polit [20].

Moreover, this refined model (see Vidal and Polit [29]) takes into account the continuity conditions between layers of the laminate for both displacements and transverse shear stresses, and the free conditions on the upper and lower surfaces.

The important feature in this new model is the introduction of both a layer refinement with physical meaning and the transverse normal effect in the framework of plate structures.

For this, the model kinematics is written in terms of Heaviside function according to the following particular form:

$$
\left\{\begin{array}{c}
U_{1}\left(x_{1}, x_{2}, z\right)=u_{0}\left(x_{1}, x_{2}\right)+z u_{1}\left(x_{1}, x_{2}\right)+f(z)\left(w_{0,1}\left(x_{1}, x_{2}\right)+\theta_{2}\left(x_{1}, x_{2}\right)\right) \\
+\sum_{k=1}^{N C}\left(\bar{u}_{l o c}^{(k)}\left(x_{1}, x_{2}, z\right)+\hat{u}_{l o c}^{(k)}\left(x_{1}, x_{2}, z\right)\right) \\
\times\left(H\left(z-z_{k}\right)-H\left(z-z_{k+1}\right)\right), \\
U_{2}\left(x_{1}, x_{2}, z\right)=v_{0}\left(x_{1}, x_{2}\right)+z v_{1}\left(x_{1}, x_{2}\right)+f(z)\left(w_{0,2}\left(x_{1}, x_{2}\right)-\theta_{1}\left(x_{1}, x_{2}\right)\right) \\
+\sum_{k=1}^{N C}\left(\bar{v}_{l o c}^{(k)}\left(x_{1}, x_{2}, z\right)+\hat{v}_{l o c}^{(k)}\left(x_{1}, x_{2}, z\right)\right) \\
\times\left(H\left(z-z_{k}\right)-H\left(z-z_{k+1}\right)\right), \\
U_{3}\left(x_{1}, x_{2}, z\right)=w_{0}\left(x_{1}, x_{2}\right)+z w_{1}\left(x_{1}, x_{2}\right)+z^{2} w_{2}\left(x_{1}, x_{2}\right),
\end{array}\right.
$$

where $H$ is the Heaviside function defined by

$\left\{H\left(z-z_{k}\right)=1 \quad\right.$ if $z \geqslant z_{k}$

$\left\{H\left(z-z_{k}\right)=0\right.$ otherwise.

In Eq. (4), $\left(u_{0}, v_{0}, w_{0}\right)$ are the displacements of a point of the middle surface while $\left(v_{1}, \theta_{1}\right)$ and $\left(u_{1}, \theta_{2}\right)$ are measurements of rotations of the normal transverse fiber around the axis $\left(0, x_{1}\right)$ and $\left(0, x_{2}\right)$, respectively. The local functions $\bar{u}_{l o c}^{(k)}, \hat{u}_{l o c}^{(k)}$ and $\bar{v}_{l o c}^{(k)}, \hat{v}_{l o c}^{(k)}$ are based on Legendre polynomials and can be written as:

$$
\begin{aligned}
& \left\{\begin{array}{l}
\bar{u}_{l o c}^{(k)}\left(x_{1}, x_{2}, z\right)=\zeta_{k} u_{31}^{k}\left(x_{1}, x_{2}\right)+\left(-\frac{1}{2}+\frac{3 \zeta_{k}^{2}}{2}\right) u_{32}^{k}\left(x_{1}, x_{2}\right), \\
\hat{u}_{l o c}^{(k)}\left(x_{1}, x_{2}, z\right)=\left(-\frac{3 \zeta_{k}}{2}+\frac{\zeta_{k}^{3}}{2}\right) u_{33}^{k}\left(x_{1}, x_{2}\right),
\end{array}\right. \\
& \left\{\begin{array}{l}
\bar{v}_{l o c}^{(k)}\left(x_{1}, x_{2}, z\right)=\zeta_{k} v_{31}^{k}\left(x_{1}, x_{2}\right)+\left(-\frac{1}{2}+\frac{3 \zeta_{k}^{2}}{2}\right) v_{32}^{k}\left(x_{1}, x_{2}\right), \\
\hat{v}_{l o c}^{(k)}\left(x_{1}, x_{2}, z\right)=\left(-\frac{3 \zeta_{k}}{2}+\frac{5 \zeta_{k}^{3}}{2}\right) v_{33}^{k}\left(x_{1}, x_{2}\right) .
\end{array}\right.
\end{aligned}
$$

A non-dimensional coordinate is introduced by: $\zeta_{k}=a_{k} z-b_{k}$, with $a_{k}=\frac{2}{z_{k+1}-z_{k}}, b_{k}=\frac{z_{k+1}+z_{k}}{z_{k+1}-z_{k}}$. The coordinate system is precised in Fig. 2 .

Finally, the functions $\left(w_{1}, w_{2}\right)$ permit to have a non-constant deflection for the transverse fiber and allow to have non zero transverse normal strain. Furthermore, the Poisson or thickness locking is avoided assuming an order two for the transverse displacement, see the work of Carrera and Brischetto [30].

In the context of the sinus model, we have:

$f(z)=\frac{h}{\pi} \sin \frac{\pi z}{h}$.

It must be noticed that the classical homogeneous sinus model [24] can be recovered from Eq. (4) assuming $w_{0,1}=-u_{1}, w_{0,2}=-v_{1}$ on the one hand, and neglecting unknown functions $w_{1}, w_{2}$ and the local thickness functions $\bar{u}_{l o c}^{(k)}, \hat{u}_{l o c}^{(k)}, \bar{v}_{l o c}^{(k)}$ and $\hat{v}_{l o c}^{(k)}$, on the other hand. The choice of the sine function can be justified from the three-dimensional point of view, using the work of Cheng [31]. As it can be seen in Polit and Touratier [21], a sine term appears in the solution of the shear equation (see Eq. (7) in [21]). Therefore, the kinematics proposed can be seen as an approximation of the exact three-dimensional solution. Furthermore, the sine function has an infinite radius of convergence and its Taylor expansion includes not only the third order terms but all the odd terms.

At this stage, $6 \times N C+9$ generalized displacements are included in Eqs. (4)-(6). In the following, the number of unknown parameters is reduced through some relations issued from:

- lateral boundary conditions at top and bottom of the plate,

- interlaminar continuity conditions (displacements, transverse shear stresses).

\subsubsection{Continuity conditions and free conditions}

From the displacement field Eq. (4), continuity conditions on displacements and stresses must be imposed. For an interface layer $k \in\{2, \ldots, N C\}$, we have:

- the displacement continuity conditions as in Sze et al. [32] i.e.:

$$
\begin{cases}\bar{u}_{l o c}^{(k)}\left(x_{1}, x_{2}, z_{k}\right)=\bar{u}_{l o c}^{(k-1)}\left(x_{1}, x_{2}, z_{k}\right) & k=2, \ldots, N C, \\ \hat{u}_{l o c}^{(k)}\left(x_{1}, x_{2}, z_{k}\right)=\hat{u}_{l o c}^{(k-1)}\left(x_{1}, x_{2}, z_{k}\right) & k=2, \ldots, N C,\end{cases}
$$

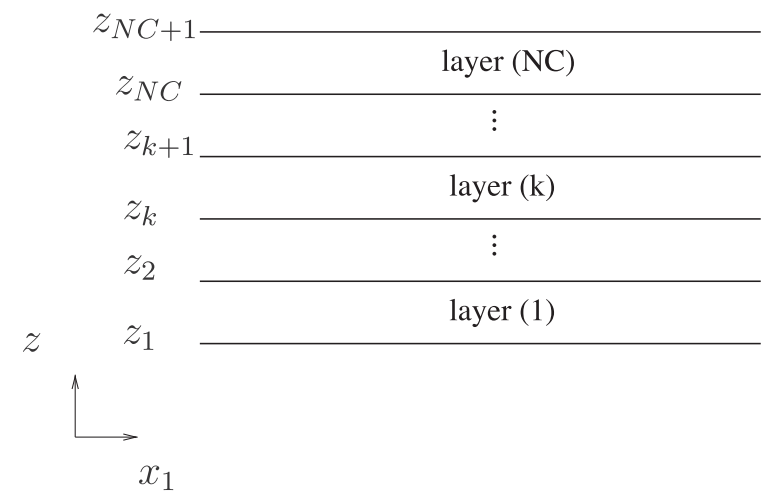

Fig. 2. Transverse coordinate of laminated plate. 


$$
\begin{cases}\bar{v}_{l o c}^{(k)}\left(x_{1}, x_{2}, z_{k}\right)=\bar{v}_{l o c}^{(k-1)}\left(x_{1}, x_{2}, z_{k}\right) & k=2, \ldots, N C, \\ \hat{v}_{l o c}^{(k)}\left(x_{1}, x_{2}, z_{k}\right)=\hat{v}_{l o c}^{(k-1)}\left(x_{1}, x_{2}, z_{k}\right) & k=2, \ldots, N C,\end{cases}
$$

- the transverse shear stresses continuity conditions between two adjacent layers:

$$
\begin{array}{ll}
\sigma_{13}^{(k)}\left(x_{1}, x_{2}, z_{k}^{+}\right)=\sigma_{13}^{(k-1)}\left(x_{1}, x_{2}, z_{k}^{-}\right) & k=2, \ldots, N C, \\
\sigma_{23}^{(k)}\left(x_{1}, x_{2}, z_{k}^{+}\right)=\sigma_{23}^{(k-1)}\left(x_{1}, x_{2}, z_{k}^{-}\right) & k=2, \ldots, N C .
\end{array}
$$

This way, $6 \times(N C-1)$ conditions are imposed, which allows to reduce the number of unknowns to 15 generalized displacements.

Free conditions of the transverse shear stresses on the upper and lower surfaces must also be verified:

$$
\begin{aligned}
& \sigma_{13}^{(1)}\left(x_{1}, x_{2}, z=-\frac{h}{2}\right)=0 \quad \text { and } \quad \sigma_{13}^{(\mathrm{NC})}\left(x_{1}, x_{2}, z=\frac{h}{2}\right)=0, \\
& \sigma_{23}^{(1)}\left(x_{1}, x_{2}, z=-\frac{h}{2}\right)=0 \quad \text { and } \quad \sigma_{23}^{(\mathrm{NC})}\left(x_{1}, x_{2}, z=\frac{h}{2}\right)=0 .
\end{aligned}
$$

The number of generalized displacements is reduced to 11 , and is independent of the number of layers. The herewith unknowns are $u_{0}, u_{1}, \theta_{2}, v_{0}, v_{1}, \theta_{1}, w_{0}, w_{1}, w_{2}, u_{31}^{1}$ and $v_{31}^{1}$. The resulting model will be denoted SinRefc-11p.

\subsection{The strain}

From the displacement field Eq. (4) and the physical considerations given in Eqs. (8)-(11), the strain components for a crossply composite plate are deduced as:

$$
\left\{\begin{aligned}
\varepsilon_{11}= & u_{0,1}+z u_{1,1}+\left(f(z)+S_{u \beta}(z)\right)\left(w_{0,11}+\theta_{2,1}\right) \\
& +S_{u \delta}(z) u_{31,1}^{1}+S_{u \lambda}(z) w_{1,11}+S_{u \mu}(z) w_{2,11} \\
& +S_{u \eta}(z)\left(w_{0,11}+u_{1,1}\right) \\
\varepsilon_{22}= & v_{0,2}+z v_{1,2}+\left(f(z)+S_{v \beta}(z)\right)\left(w_{0,22}-\theta_{1,2}\right) \\
& +S_{v \delta}(z) v_{31,2}^{1}+S_{v \lambda}(z) w_{1,22}+S_{v \mu}(z) w_{2,22} \\
& +S_{v \eta}(z)\left(w_{0,22}+v_{1,2}\right) \\
\varepsilon_{33}= & w_{1}+2 z w_{2}, \\
\gamma_{23}= & \left(f(z)_{, 3}+S_{v \beta}(z)_{, 3}\right)\left(w_{0,2}-\theta_{1}\right)+S_{v \delta}(z)_{, 3} v_{31}^{1} \\
& +\left(1+S_{v \eta}(z)_{, 3}\right)\left(w_{0,2}+v_{1}\right) \\
& +\left(z+S_{v \lambda}(z)_{, 3}\right) w_{1,2}+\left(z^{2}+S_{v \mu}(z)_{, 3}\right) w_{2,2} \\
\gamma_{13}= & \left(f(z)_{, 3}+S_{u \beta}(z)_{, 3}\right)\left(w_{0,1}+\theta_{2}\right)+S_{u \delta}(z)_{, 3} u_{31}^{1} \\
& +\left(1+S_{u \eta}(z)_{, 3}\right)\left(w_{0,1}+u_{1}\right) \\
& +\left(z+S_{u \lambda}(z)_{, 3}\right) w_{1,1}+\left(z^{2}+S_{u \mu}(z)_{, 3}\right) w_{2,1} \\
\gamma_{12}=u_{0,2}+v_{0,1}+z\left(u_{1,2}+v_{1,1}\right)+\left(f(z)+S_{u \beta}(z)\right)\left(w_{0,12}+\theta_{2,2}\right) & +\left(f(z)+S_{v \beta}(z)\right)\left(w_{0,12}-\theta_{1,1}\right)+S_{u \delta}(z) u_{31,2}^{1}+S_{v \delta}(z) v_{31,1}^{1} \\
& +\left(S_{u \lambda}(z)+S_{v \lambda}(z)\right) w_{1,12}+\left(S_{u \mu}(z)+S_{v \mu}(z)\right) w_{2,12} \\
& +S_{u \eta}(z)\left(w_{0,12}+u_{1,2}\right)+S_{v \eta}(z)\left(w_{0,12}+v_{1,1}\right) \\
& \\
& (f)
\end{aligned}\right.
$$

The expressions of the continuity functions $S_{u \times}(z)$ and $S_{v \times}(z)$ are given in Appendix A. Note that the expressions associated with the angle-ply plate are not given here for brevity reason.

\subsection{The matrix expression for displacement and strain}

Matrix notation for the displacement field defined in Eq. (4) can be written using a generalized displacement vector as:

$$
\begin{aligned}
& {[u]^{T}=\left[F_{u}(z)\right]\left[\mathcal{E}_{u}\right] \text { with }}
\end{aligned}
$$

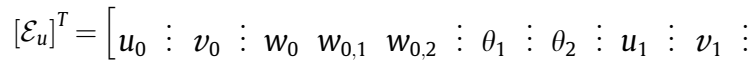

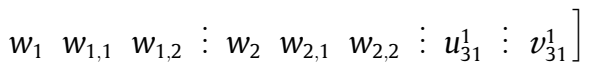$$
[u]^{T}=\left[\begin{array}{lll}
U_{1} & U_{2} & U_{3}
\end{array}\right]
$$

where $\left[F_{u}(z)\right]$ depends on the normal coordinate $z$ and is given in Appendix A.

In a similar manner, from Eq. (12), the following expression can be deduced for the strain field:

$[\varepsilon]^{T}=\left[F_{\varepsilon}(z)\right]\left[\mathcal{E}_{\varepsilon}\right]$ with

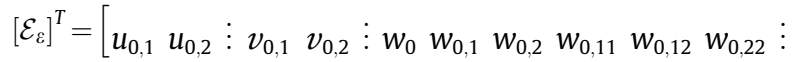

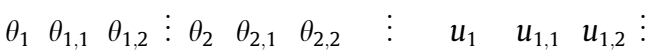

$\begin{array}{llllllllll}v_{1} & v_{1,1} & v_{1,2} & \vdots & w_{1} & w_{1,1} & w_{1,2} & w_{1,11} & w_{1,12} & w_{1,22}\end{array} \vdots$

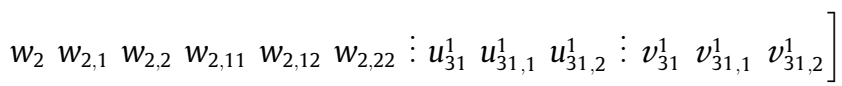

where $\left[F_{\varepsilon}(z)\right]$ is deduced from Eqs. (13) and (A.3), and is not given for brevity reason.

\subsection{The matrix expression of the weak form of the boundary value problem}

Using the constitutive relation given in Eq. (1), the matrix expression for the displacement and strain fields, Eqs. (13) and (14), the following expressions are obtained for each term of Eq. (3):

$$
\begin{aligned}
& \int_{\mathcal{V}}\left[\varepsilon\left(\vec{u}^{*}\right)\right]^{T}[\sigma(\vec{u})] d \mathcal{V}=\int_{\mathcal{V}}\left[\mathcal{E}_{\varepsilon}^{*}\right]^{T}\left[F_{\varepsilon}(z)\right]^{T}[C]\left[F_{\varepsilon}(z)\right]\left[\mathcal{E}_{\varepsilon}\right] d \mathcal{V}, \\
& \int_{\mathcal{V}}\left[u^{*}\right]^{T}[f] d \mathcal{V}+\int_{\partial \mathcal{V}_{F}}\left[u^{*}\right]^{T}[F] d \partial \mathcal{V} \\
& =\int_{\mathcal{V}}\left[\mathcal{E}_{u}^{*}\right]^{T}\left[F_{u}(z)\right]^{T}[f] d \mathcal{V}+\int_{\partial \mathcal{V}_{F}}\left[\mathcal{E}_{u}^{*}\right]^{T}\left[F_{u}(z)\right]^{T}[F] d \partial \mathcal{V},
\end{aligned}
$$

where $[C]$ stands for the three dimensional stiffness coefficient, see Eq. (1). In these last expressions, the integration throughout the thickness can be explicitly carried out taking into account the stacking sequence of the laminae. The integration with respect to the inplane domain $\Omega$ is kept:

$$
\begin{gathered}
\int_{\mathcal{V}}\left[\varepsilon\left(\vec{u}^{*}\right)\right]^{T}[\sigma(\vec{u})] d \mathcal{V}=\int_{\Omega}\left[\mathcal{E}_{\varepsilon}^{*}\right]^{T}\left[k_{\varepsilon \varepsilon}\right]\left[\mathcal{E}_{\varepsilon}\right] d \Omega \\
\text { with } \quad\left[k_{\varepsilon \varepsilon}\right]=\int_{-h / 2}^{h / 2}\left[F_{\varepsilon}(z)\right]^{T}[C]\left[F_{\varepsilon}(z)\right] d z, \\
\int_{\mathcal{V}}\left[u^{*}\right]^{T}[f] d \mathcal{V}=\int_{\Omega}\left[\mathcal{E}_{u}^{*}\right]^{T}\left[b_{u}\right][f] d \mathcal{V} \\
\text { with } \quad\left[b_{u}\right]=\int_{-h / 2}^{h / 2}\left[F_{u}(z)\right]^{T} d z,
\end{gathered}
$$

where the matrix $\left[k_{\varepsilon \varepsilon}\right]$ can be viewed as the integration over the thickness of the constitutive relations.

Eq. (16) is a good starting point for finite element approximations of the displacement. The generalized displacement and strain vectors defined by $\left[\mathcal{E}_{u}\right]$ and $\left[\mathcal{E}_{\varepsilon}\right]$, see respectively Eqs. (13) and (14), must be approximated and this will be described in the next section. 


\section{The finite element approximations: the triangular six-node FE}

This section is dedicated to the finite element approximations of the generalized displacement and strain vectors $\left(\left[\mathcal{E}_{u}\right],\left[\mathcal{E}_{\varepsilon}\right]\right)$ defined in the previous section.

\subsection{Elementary stiffness matrix}

The elementary stiffness matrix $\left[K_{e}\right]$ is deduced from Eq. (16) at the elementary level as:

$\int_{\Omega_{e}}\left[\mathcal{E}_{\varepsilon_{e}}^{* h}\right]^{T}\left[k_{\varepsilon \varepsilon}\right]\left[\mathcal{E}_{\varepsilon_{e}}^{h}\right] d \Omega_{e}=\left[Q_{e}^{*}\right]^{T}\left[K_{e}\right]\left[Q_{e}\right]$,

where $\Omega_{e}$ refers to one element of the triangulation of the multilayered structure $\cup \Omega_{e}$. The superscript $h$ indicates the finite element approximation. $\left[Q_{e}\right]$ is the elementary vector of dofs in global coordinates.

From Eq. (12), the unknowns associated with the deflection $w_{0}^{h}, w_{1}^{h}, w_{2}^{h}$ must be at least $C^{1}$-continuous functions. Generalized membrane displacements $u_{0}^{h}$ and $v_{0}^{h}$, generalized shear rotation $\theta_{\alpha}^{h}$, and $u_{1}^{h}, v_{1}^{h}$ and generalized refined functions $\left(u_{31}^{1 h}, v_{31}^{1 h}\right)$ can be therefore $\mathrm{C}^{0}$-continuous. In order to develop a conform FE approximation, we choose the Argyris interpolation for the transverse displacements and the Ganev interpolation for the other generalized displacements. Since the Argyris interpolation is a polynomia of the fifth order and the Ganev interpolation of the fourth order, we can immediately conclude that the transverse shear locking is avoided as the field compatibility is automatically ensured for the transverse shear strains, see for example [33]. Note that the Argyris interpolation is a $\mathrm{C}^{1} \mathrm{FE}$ approximation, and the Ganev interpolation involves a semi- $\mathrm{C}^{1}$ continuity. Due to the very long expressions for these interpolations, the reader is referred to either the original papers of Argyris et al. [34] and Ganev and Dimitrov [35], or to a more recent book of Bernadou [36].

Figs. 3 and 4 show the local degrees of freedom for the approximations of $w_{0}^{h}, w_{1}^{h}, w_{2}^{h}$ and $u_{\alpha}^{h} ; v_{\alpha}^{h} ; \theta_{\alpha}^{h} ; u_{31}^{1 h}, v_{31}^{1 h}$ respectively. The discrete form of the vector $\left[\mathcal{E}_{\varepsilon_{e}}^{h}\right.$ (idem for $\left[\mathcal{E}_{\varepsilon_{e}}^{* h}\right]$ adding an asterisk superscript on the degrees of freedom) may therefore be written as:

$\left[\mathcal{E}_{\varepsilon_{e}}^{h}\right]=[\Lambda k]\left[T k_{e}\right]\left[D_{e}\right]\left[Q_{e}\right]$,

where $\left[D_{e}\right]$ is a geometric transformation matrix between local and global degrees of freedom. This vector contains the degrees of freedom of the three corner nodes and of the three mid-side nodes (which are not the same):

- for a corner node, we have the following degrees of freedom:

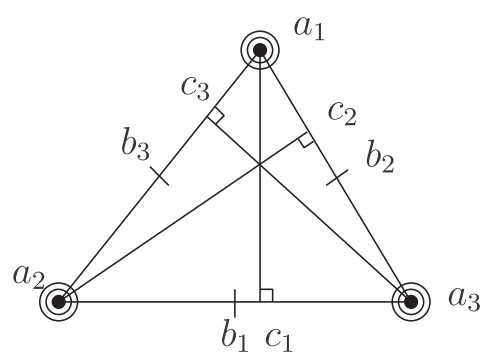

$\mathrm{D}_{K}=P_{5}(K) ; \operatorname{dim}\left(P_{K}\right)=21$

$\Sigma_{K}=\left\{p\left(a_{i}\right), D p\left(a_{i}\right)\left(a_{i-1}-a_{i}\right), D p\left(a_{i}\right)\left(a_{i+1}-a_{i}\right), 1 \leq i \leq 3 ;\right.$

$D^{2} p\left(a_{i}\right)\left(a_{j+1}-a_{j-1}\right)^{2}, 1 \leq i, j \leq 3 ; D p\left(b_{i}\right)\left(a_{i}-c_{i}\right), 1 \leq i \leq 3$

Fig. 3. The set $\Sigma_{K}$ of local dof of a function $p$ for an Argyris triangle.

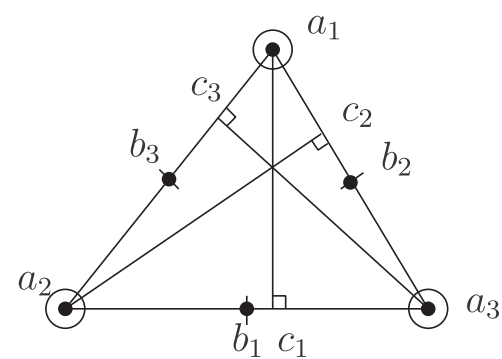

$$
\begin{aligned}
P_{K}= & P_{4}(K) ; \operatorname{dim}\left(P_{K}\right)=15 \\
\Sigma_{K}= & \left\{p\left(a_{i}\right), D p\left(a_{i}\right)\left(a_{i-1}-a_{i}\right),\right. \\
& \left.D p\left(a_{i}\right)\left(a_{i+1}-a_{i}\right), p\left(b_{i}\right), D p\left(b_{i}\right)\left(a_{i}-c_{i}\right), 1 \leq i \leq 3\right\}
\end{aligned}
$$

Fig. 4. The set $\Sigma_{K}$ of local dof of a function $p$ for a Ganev triangle.

$\begin{array}{cccccc}u_{0} & u_{0,1} & u_{0,2} & v_{0} & v_{0,1} & v_{0,2} \\ w_{0} & w_{0,1} & w_{0,2} & w_{0,11} & w_{0,22} & w_{0,12} \\ \theta_{1} & \theta_{1,1} & \theta_{1,2} & \theta_{2} & \theta_{2,1} & \theta_{2,2} \\ u_{1} & u_{1,1} & u_{1,2} & v_{1} & v_{1,1} & v_{1,2} \\ w_{1} & w_{1,1} & w_{1,2} & w_{1,11} & w_{1,22} & w_{1,12} \\ w_{2} & w_{2,1} & w_{2,2} & w_{2,11} & w_{2,22} & w_{2,12} \\ u_{31}^{1} & u_{31,1}^{1} & u_{31,2}^{1} & v_{31}^{1} & v_{31,1}^{1} & v_{31,2}^{1}\end{array}$

- while, for a mid-side node, they are:

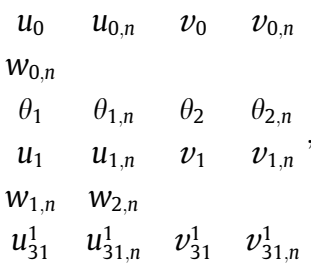

where $p_{n}$ is the derivative with respect to the normal direction of the edge. Finally, in Eq. (18), the matrix $[\Lambda k]$ is expressed as a function of barycentric coordinates, while $\left[T k_{e}\right]$ only contains geometric constants, so that the product $[\Lambda k]\left[T k_{e}\right]$ may be seen as the interpolations with respect to the local degrees of freedom (see Figs. 3 and 4 ) for the components of the vector $\left[\mathcal{E}_{\varepsilon_{e}}^{h}\right]\left(\left[\mathcal{E}_{\varepsilon_{e}}^{* h}\right]\right)$.

From Eqs. (17) and (18), the elementary stiffness matrix can be written as:

$\left[K_{e}\right]=\int_{\Omega_{e}}\left[D_{e}\right]^{T}\left[T k_{e}\right]^{T}[\Lambda k]^{T}\left[k_{\varepsilon \varepsilon}\right][\Lambda k]\left[T k_{e}\right]\left[D_{e}\right] d \Omega_{e}$.

The matrices $\left[D_{e}\right],\left[T k_{e}\right],[\Lambda k]$ are detailed in Bernadou [36].

The exact numerical integration rule for the $\left[K_{e}\right]$ matrix is given in Dunavant [37] and requires 16 points for the shear part of this stiffness matrix. The same rule has been used for membrane, bending and refined bending parts.

The expression of the load vectors is classical and not precised here for the sake of brevity. For more details, the reader can refer to the work of Polit and Touratier [21].

Table 1

Conditions on dofs for the two interpolations.

\begin{tabular}{lllllllll}
\hline Edge & Interpolation & $p$ & $p_{, 1}$ & $p_{, 2}$ & $p_{, n}$ & $p_{, 11}$ & $p_{, 22}$ & $p_{, 12}$ \\
\hline$x_{1}=\mathrm{cst}$ & GANEV & 0 & 1 & 0 & 1 & - & - & - \\
& ARGYRIS & 0 & 1 & 0 & 1 & 1 & 0 & 1 \\
$x_{2}=\mathrm{cst}$ & GANEV & 0 & 0 & 1 & 1 & - & - & - \\
& ARGYRIS & 0 & 0 & 1 & 1 & 0 & 1 & 1 \\
\hline
\end{tabular}

0: Fixed; 1: free; -: unavailable. 


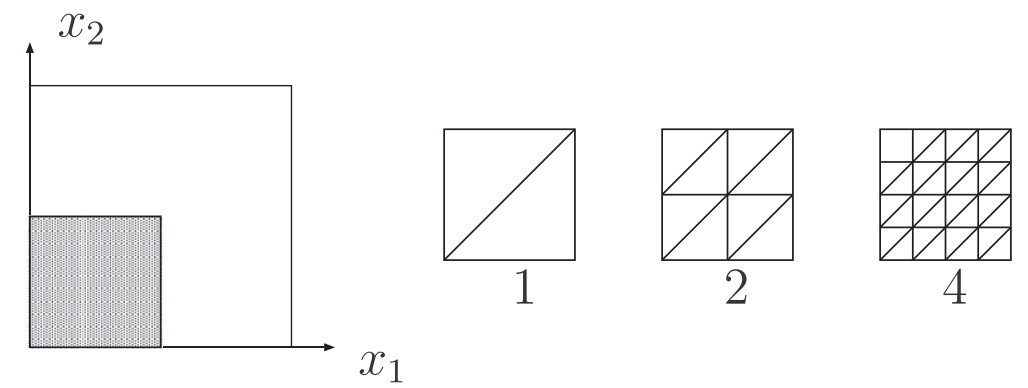

Fig. 5. The meshes used $(N=1,2,4)$ for numerical evaluations.

\subsection{Boundary conditions}

The boundary conditions to be satisfied on the generalized displacements for a simply supported rectangular plate of plane-form dimensions $a$ and $b$ are given by:

- edges $x_{1}=0$ and $x_{1}=a$ for all $x_{2} \in[0, b]$ :

$$
v_{0}^{h}=v_{1}^{h}=w_{0}^{h}=\theta_{1}^{h}=w_{1}^{h}=w_{2}^{h}=v_{31}^{1 h}=0 .
$$

- edge $x_{2}=0$ and $x_{2}=b$ for all $x_{1} \in[0, a]$ :

$$
u_{0}^{h}=u_{1}^{h}=w_{0}^{h}=\theta_{2}^{h}=w_{1}^{h}=w_{2}^{h}=u_{31}^{1 h}=0 .
$$

These conditions on the generalized displacements depending of the type of interpolation can be deduced on the dofs using Table 1 . Note that these boundary conditions can be managed automatically using a reference number.

From this table, the generalized displacements concerned by the analytical boundary conditions specified above, and the degrees of freedom for each node (see (19) and (20)), it is easy to obtain all the degrees of freedom that must be nil.

\section{The numerical results}

In this section, several static tests available in open literature are presented for validating our finite element and evaluating its efficiency. The properties of the FE are assessed. The results are discussed for mechanical and thermal loads.

The comparisons will involve simpler refined kinematics models with the same FE approximation based on Argyris-Ganev interpolations $[25,33,38]$ :

Sin Sinus model with five unknown functions.

Sinc Sinus model with interlayer continuity conditions ensured by a Heaviside function. Five unknown functions are used.

FSDT Reissner-Mindlin model where the classical shear correction factor $5 / 6$ is used.

CLT Kirchhoff-Love model.

Furthermore, the reference is also made to the systematic work of Carrera and his "Carrera Unified Formulation" (CUF), see [39-41]:

Table 2

\begin{tabular}{|c|c|c|c|c|c|c|c|c|c|}
\hline \multirow[t]{3}{*}{$S$} & \multirow[t]{3}{*}{$\mathrm{Nb}$ dofs } & \multicolumn{4}{|l|}{ SinRefc-11p } & \multicolumn{3}{|l|}{ [19] } & \multirow[t]{3}{*}{ Exact } \\
\hline & & $N=1$ & $N=2$ & $N=4$ & $N=8$ & $N=8$ & $N=16$ & $N=20$ & \\
\hline & & 121 & 440 & 1672 & 6512 & 1186 & 4802 & 7522 & \\
\hline \multirow[t]{4}{*}{2} & $\bar{U}_{3}$ & $5.1098(0.3 \%)$ & $5.1116(0.3 \%)$ & $5.1117(0.3 \%)$ & $5.1117(0.3 \%)$ & - & - & - & 5.0954 \\
\hline & $\bar{\sigma}_{13}$ & $0.1637(0.1 \%)$ & $0.1636(0.2 \%)$ & $0.1636(0.2 \%)$ & $0.1636(0.2 \%)$ & $0.1600(2.4 \%)$ & $0.1631(0.5 \%)$ & $0.1639(0.1 \%)$ & 0.1640 \\
\hline & $\bar{\sigma}_{23}$ & $0.2656(2.5 \%)$ & $0.2655(2.5 \%)$ & $0.2655(2.5 \%)$ & $0.2655(2.5 \%)$ & $0.2791(7.7 \%)$ & $0.2817(8.7 \%)$ & $0.2820(8.8 \%)$ & 0.2591 \\
\hline & $\bar{\sigma}_{33}$ & $0.4293(4.5 \%)$ & $0.4387(2.4 \%)$ & $0.4410(1.9 \%)$ & $0.4411(1.8 \%)$ & $0.5194(15.6 \%)$ & $0.4774(6.3 \%)$ & $0.4516(0.5 \%)$ & 0.4493 \\
\hline \multirow[t]{4}{*}{4} & $\bar{U}_{3}$ & $2.007(0.0 \%)$ & $2.008(0.1 \%)$ & $2.008(0.1 \%)$ & $2.008(0.1 \%)$ & - & - & - & 2.006 \\
\hline & $\bar{\sigma}_{13}$ & $0.2558(0.0 \%)$ & $0.2556(0.1 \%)$ & $0.2556(0.1 \%)$ & $0.2556(0.1 \%)$ & $0.2515(1.7 \%)$ & $0.2557(0.1 \%)$ & $0.2562(0.1 \%)$ & 0.2559 \\
\hline & $\bar{\sigma}_{23}$ & $0.2199(1.2 \%)$ & $0.2190(0.8 \%)$ & $0.2190(0.8 \%)$ & $0.2190(0.8 \%)$ & $0.2180(0.4 \%)$ & $0.2185(0.6 \%)$ & $0.2184(0.6 \%)$ & 0.2172 \\
\hline & $\bar{\sigma}_{33}$ & $0.4666(5.3 \%)$ & $0.4800(2.6 \%)$ & $0.4832(1.9 \%)$ & $0.4834(1.9 \%)$ & $0.5530(12.3 \%)$ & $0.5373(9.1 \%)$ & $0.5111(3.8 \%)$ & 0.4927 \\
\hline \multirow[t]{4}{*}{10} & $\bar{U}_{3}$ & $0.7528(0.0 \%)$ & $0.7531(0.0 \%)$ & $0.7531(0.0 \%)$ & $0.7531(0.0 \%)$ & - & - & - & 0.7530 \\
\hline & $\bar{\sigma}_{13}$ & $0.3577(0.1 \%)$ & $0.3572(0.0 \%)$ & $0.3573(0.0 \%)$ & $0.3573(0.0 \%)$ & $0.3471(2.9 \%)$ & $0.3562(0.3 \%)$ & $0.3574(0.0 \%)$ & 0.3573 \\
\hline & $\bar{\sigma}_{23}$ & $0.1249(1.7 \%)$ & $0.1232(0.4 \%)$ & $0.1232(0.4 \%)$ & $0.1232(0.4 \%)$ & $0.1227(0.1 \%)$ & $0.1220(0.7 \%)$ & $0.1215(1.1 \%)$ & 0.1228 \\
\hline & $\bar{\sigma}_{33}$ & $0.4747(5.0 \%)$ & $0.4910(1.7 \%)$ & $0.4964(0.6 \%)$ & $0.4968(0.5 \%)$ & $0.5125(2.6 \%)$ & $0.5191(3.9 \%)$ & $0.5068(1.5 \%)$ & 0.4994 \\
\hline \multirow[t]{4}{*}{20} & $\bar{U}_{3}$ & $0.5163(0.0 \%)$ & $0.5164(0.0 \%)$ & $0.5164(0.0 \%)$ & $0.5164(0.0 \%)$ & - & - & - & 0.5164 \\
\hline & $\bar{\sigma}_{13}$ & $0.3858(0.3 \%)$ & $0.3846(0.0 \%)$ & $0.3846(0.0 \%)$ & $0.3846(0.0 \%)$ & $0.3662(4.8 \%)$ & $0.3793(1.4 \%)$ & $0.3818(0.7 \%)$ & 0.3846 \\
\hline & $\bar{\sigma}_{23}$ & $0.0971(3.5 \%)$ & $0.0942(0.4 \%)$ & $0.0941(0.4 \%)$ & $0.0941(0.4 \%)$ & $0.0936(0.2 \%)$ & $0.0945(0.7 \%)$ & $0.0942(0.4 \%)$ & 0.0938 \\
\hline & $\bar{\sigma}_{33}$ & $0.4728(5.4 \%)$ & $0.4879(2.4 \%)$ & $0.4980(0.4 \%)$ & $0.4988(0.2 \%)$ & - & - & - & 0.4999 \\
\hline \multirow[t]{4}{*}{50} & $\bar{U}_{3}$ & $0.4450(0.0 \%)$ & $0.4451(0.0 \%)$ & $0.4451(0.0 \%)$ & $0.4451(0.0 \%)$ & - & - & - & 0.4451 \\
\hline & $\bar{\sigma}_{13}$ & $0.3984(1.3 \%)$ & $0.3935(0.0 \%)$ & $0.3934(0.0 \%)$ & $0.3934(0.0 \%)$ & $0.3534(10.1 \%)$ & $0.3793(3.5 \%)$ & $0.3828(2.6 \%)$ & 0.3934 \\
\hline & $\bar{\sigma}_{23}$ & $0.0901(7.0 \%)$ & $0.0847(0.5 \%)$ & $0.0846(0.4 \%)$ & $0.0845(0.4 \%)$ & $0.0897(6.5 \%)$ & $0.0851(1.1 \%)$ & $0.0850(1.0 \%)$ & 0.0842 \\
\hline & $\bar{\sigma}_{33}$ & $0.4677(6.5 \%)$ & $0.4720(5.6 \%)$ & $0.4964(0.7 \%)$ & $0.4992(0.2 \%)$ & - & - & - & 0.5000 \\
\hline \multirow[t]{4}{*}{100} & $\bar{U}_{3}$ & $0.4347(0.0 \%)$ & $0.4347(0.0 \%)$ & $0.4347(0.0 \%)$ & $0.4347(0.0 \%)$ & - & - & - & 0.4347 \\
\hline & $\bar{\sigma}_{13}$ & $0.4050(2.6 \%)$ & $0.3953(0.2 \%)$ & $0.3947(0.0 \%)$ & $0.3947(0.0 \%)$ & - & - & - & 0.3947 \\
\hline & $\bar{\sigma}_{23}$ & $0.0898(8.5 \%)$ & $0.0832(0.5 \%)$ & $0.0831(0.4 \%)$ & $0.0831(0.4 \%)$ & - & - & - & 0.0828 \\
\hline & $\bar{\sigma}_{33}$ & $0.4662(6.8 \%)$ & $0.4546(9.1 \%)$ & $0.4925(1.5 \%)$ & $0.4988(0.2 \%)$ & - & - & - & 0.5000 \\
\hline
\end{tabular}

Convergence study for simply supported three-layered square plate. 


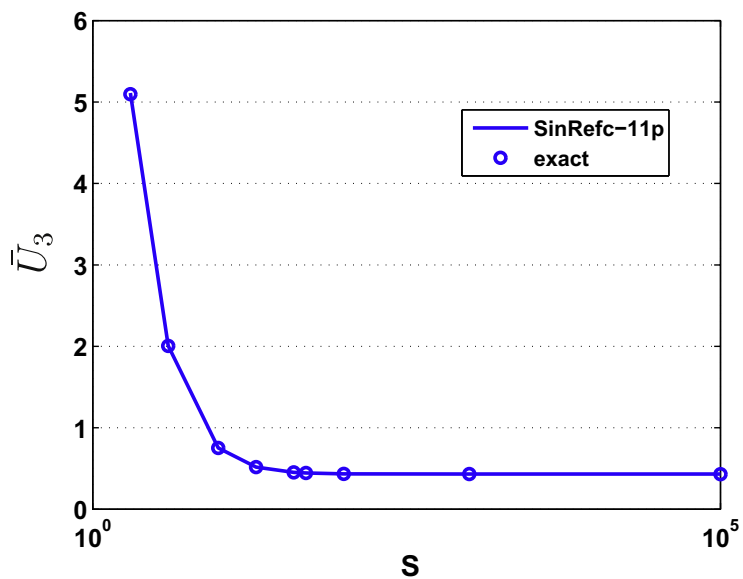

Fig. 6. Variation of the non-dimensional transverse displacement with respect to aspect ratio $S-\bar{U}_{3}=U_{3}(a / 2, b / 2,0) \frac{100 E_{L}}{q_{0} h S^{4}}$ - three layers $\left(0^{\circ} / 90^{\circ} / 0^{\circ}\right)$; mesh $N=2$; SinRefc-11p model.

ED3 Equivalent single layer and displacement approach, each component is expanded until the third order; twelve unknown functions are used in this kinematic.

EDZ3 Equivalent single layer and displacement approach, each component is expanded until the second order and this expansion is extended by the Murakami zig-zag function; twelve unknown functions are used in this kinematic.

LD2 Layerwise approach and displacement approach, each component is expanded until the second order in each layer; $3(2 N C+1)$ unknown functions are used in this kinematic.

The meshes and the notations are illustrated in Fig. 5.

\subsection{Convergence study}

Before proceeding to the detailed analysis, numerical computations are carried out to establish the convergence properties and the effect of aspect ratio (shear locking).

The test concerns simply supported very thick and thin symmetric composite plates and is issued from Pagano [22]. The following data are considered:

Geometry: composite cross-ply plate $\left(0^{\circ} / 90^{\circ} / 0^{\circ}\right), a=b$ and length-to-thickness ratio from $S=2$ to $100\left(S=\frac{a}{h}\right)$; a quarter of the plate is meshed. All layers have the same thickness.

Boundary conditions: simply supported plate subjected to bi-sinusoidal pressure on the top surface $q\left(x_{1}, x_{2}, z=h / 2\right)=q_{0} \sin \frac{\pi x_{1}}{a} \sin \frac{\pi x_{2}}{b}$.

Material properties:

$$
\begin{aligned}
& E_{L}=172.4 \mathrm{GPa}, \quad E_{T}=6.895 \mathrm{GPa}, \quad G_{L T}=3.448 \mathrm{GPa} \\
& G_{T T}=1.379 \mathrm{GPa}, \quad v_{L T}=v_{T T}=0.25,
\end{aligned}
$$

where $L$ refers to the fiber direction, $T$ refers to the transverse direction.

Results: displacements and stresses are made non-dimensional according to

$$
\begin{aligned}
& \bar{U}_{3}=U_{3}(a / 2, b / 2,0) \frac{100 E_{L}}{q_{0} h S^{4}}, \quad \bar{\sigma}_{13}=\sigma_{13}(0, b / 2,0) \frac{1}{q_{0} S}, \\
& \bar{\sigma}_{23}=\sigma_{23}(a / 2,0,0) \frac{1}{q_{0} S}, \quad \bar{\sigma}_{33}=\sigma_{33}(a / 2, b / 2,0) \frac{1}{q_{0}} .
\end{aligned}
$$

Table 2 gives the convergence of the SinRefc-11p model for the transverse displacement, the transverse shear stresses and the transverse normal stress for different length-to-thickness ratios. The results from Zhen and Wanji [19] are also given for comparison. It must be noticed that the convergence rate is very high. Based on progressive mesh refinement, a $N=4$ mesh is adequate to model very thick to thin laminated plates for a bending analysis. The error rate is less than $2.5 \%$ regardless of the slenderness ratio. The transverse normal stress is the most sensitive variable. Moreover, the present FE is very efficient using much less dofs compared with the three-noded triangular element in Zhen and Wanji [19]. In the latter approach, a $\mathrm{C}^{1}$ weak-continuity conditions in the interelement is satisfied. The maximum error rate is $8.8 \%(S=2)$ and $3.8 \%(S \geqslant 4)$ for $N=20$.

Considering various values for aspect ratio, the normalized displacement obtained at the center point of the plate is shown in Fig. 6 for a fixed mesh with $N=2$ along with the exact solution of Pagano [22]. They are found to be in excellent agreement. It is also inferred from Fig. 6 that the present element is free from shear locking phenomenon as the element is developed using a field compatibility approach.

\subsection{Bending analysis of laminated composite plate}

This test case proposed by Pagano [22] involves simply supported symmetric and anti-symmetric composite plates:

Geometry: rectangular $(b=3 a)$ and square plate with lengthto-thickness ratios from $S=2$ to $S=100$. All layers have the same thickness.

Boundary conditions: simply-supported plate subjected to bisinusoidal load $q\left(x_{1}, x_{2}\right)=q_{0} \sin \frac{\pi x_{1}}{a} \sin \frac{\pi x_{2}}{b}$.

Material properties: composite cross-ply plate $\left(0^{\circ} / 90^{\circ} / 0^{\circ}\right)$ and $\left(0^{\circ} / 90^{\circ}\right)$ with same properties as in 4.1 .

Mesh: $N=8$ is used for the quarter of the plate.

Results: displacements and stresses are made non-dimensional according to

$$
\begin{aligned}
& \bar{U}_{\alpha}=U_{\alpha} \frac{E_{L}}{q_{0} h S^{3}} \text { for }\left\{\begin{array}{l}
U_{1}(0, b / 2, z), \\
U_{2}(a / 2,0, z),
\end{array}\right. \\
& \bar{U}_{3}=U_{3}(a / 2, b / 2, z) \frac{100 E_{L}}{q_{0} h S^{4}}, \\
& \bar{\sigma}_{\alpha \beta}=\sigma_{\alpha \beta} \frac{1}{q_{0} S^{2}} \text { for }\left\{\begin{array}{l}
\sigma_{11}(a / 2, a / 2, z), \sigma_{22}(a / 2, a / 2, z), \\
\sigma_{12}(0,0, z),
\end{array}\right. \\
& \bar{\sigma}_{\alpha 3}=\sigma_{\alpha 3} \frac{1}{q_{0} S} \text { for }\left\{\begin{array}{l}
\sigma_{13}(0, b / 2, z), \\
\sigma_{23}(a / 2,0, z),
\end{array}\right. \\
& \bar{\sigma}_{33}=\sigma_{33}(a / 2, b / 2, z) \frac{1}{q_{0}} .
\end{aligned}
$$

Reference values are the three-dimensional exact elasticity results given by Pagano [22].

The two-layer case $\left(0^{\circ} / 90^{\circ}\right)$ is first presented for a rectangular plate. The numerical results for deflection, in-plane displacements, transverse shear stresses, and in-plane stresses are given in Table 3 with respect to span-to-thickness ratio: from $S=2$ (very thick) to $S=100$ (very thin). The error rate for the refined model, sinus model with continuity, sinus model without continuity and the classical FSDT and CLT are also compared in this table. The refined sinus approach gives more precise results than the previous sinus models ( $\mathrm{Sin}$ and Sinc) and classical ones. The error is less than $1.3 \%$ for the displacements, and less than $2.5 \%$ for the stresses with $S \geqslant 4$. Even for the very thick case, the accuracy of the results remains satisfactory. 
Table 3

Results for simply supported rectangular plate $-b=3 a-2$ layers.

\begin{tabular}{|c|c|c|c|c|c|c|c|c|c|}
\hline$S$ & & $\bar{U}_{1}(h / 2)$ & $\bar{U}_{2}(-h / 2)$ & $\bar{U}_{3}(0)$ & $\bar{\sigma}_{11}(-h / 2)$ & $\bar{\sigma}_{22}(h / 2)$ & $\bar{\sigma}_{12}(h / 2)$ & $\bar{\sigma}_{13} \max$ & $\bar{\sigma}_{23} \max$ \\
\hline \multirow[t]{6}{*}{2} & $\begin{array}{l}\text { SinRefc- } \\
11 p\end{array}$ & $-0.0851(0.1 \%)$ & $0.0387(0.7 \%)$ & $9.8771(1.3 \%)$ & $-2.2521(12.9 \%)$ & $0.6833(3.2 \%)$ & $-0.0755(0.1 \%)$ & $0.5584(4.2 \%)$ & $0.1130(0.6 \%)$ \\
\hline & Sinc & $-0.0358(57.9 \%)$ & $0.0290(24.8 \%)$ & $7.7834(22.2 \%)$ & $-2.8053(40.6 \%)$ & $0.4803(27.5 \%)$ & $-0.0458(39.3 \%)$ & $0.3588(33.1 \%)$ & $0.0732(35.6 \%)$ \\
\hline & $\operatorname{Sin}$ & $-0.0588(30.9 \%)$ & $0.0357(7.3 \%)$ & 8.6475 (13.6\%) & $-2.8980(45.3 \%)$ & $0.5164(22.0 \%)$ & $-0.0589(21.9 \%)$ & $0.5536(3.3 \%)$ & $0.1162(2.2 \%)$ \\
\hline & FSDT & $-0.0543(36.2 \%)$ & $0.0387(0.6 \%)$ & $10.4584(4.5 \%)$ & $-1.5693(21.3 \%)$ & $0.4535(31.5 \%)$ & $-0.0530(29.7 \%)$ & $0.4241(20.9 \%)$ & $0.0919(19.2 \%)$ \\
\hline & CLT & $-0.0566(33.5 \%)$ & $0.0196(49.0 \%)$ & $2.4628(75.4 \%)$ & $-1.6411(17.7 \%)$ & $0.2065(68.8 \%)$ & $-0.0393(47.9 \%)$ & $0.0000(100.0 \%)$ & $0.0000(100.0 \%)$ \\
\hline & Exact & -0.0851 & 0.0385 & 10.0073 & -1.9951 & 0.6620 & -0.0755 & 0.5361 & 0.1137 \\
\hline \multirow[t]{6}{*}{4} & $\begin{array}{l}\text { SinRefc- } \\
11 \mathrm{p}\end{array}$ & $-0.0656(0.2 \%)$ & $0.0271(0.1 \%)$ & $4.3820(0.3 \%)$ & $-1.7856(2.5 \%)$ & $0.3364(1.7 \%)$ & $-0.0499(0.1 \%)$ & $0.6492(1.4 \%)$ & $0.0776(1.9 \%)$ \\
\hline & Sinc & $-0.0506(22.8 \%)$ & $0.0238(12.2 \%)$ & $3.9500(10.1 \%)$ & $-1.9625(12.6 \%)$ & $0.2966(10.3 \%)$ & $-0.0418(16.0 \%)$ & $0.4034(37.0 \%)$ & $0.0648(14.9 \%)$ \\
\hline & $\operatorname{Sin}$ & $-0.0569(13.0 \%)$ & $0.0258(4.7 \%)$ & $4.1328(5.9 \%)$ & $-1.9751(13.3 \%)$ & $0.3093(6.5 \%)$ & $-0.0456(8.4 \%)$ & $0.6018(6.0 \%)$ & $0.0931(22.2 \%)$ \\
\hline & FSDT & $-0.0557(15.0 \%)$ & $0.0271(0.2 \%)$ & $4.4873(2.1 \%)$ & $-1.6129(7.5 \%)$ & $0.3035(8.2 \%)$ & $-0.0447(10.3 \%)$ & $0.4326(32.4 \%)$ & $0.0665(12.7 \%)$ \\
\hline & CLT & $-0.0566(13.6 \%)$ & $0.0196(27.5 \%)$ & $2.4628(43.9 \%)$ & $-1.6411(5.8 \%)$ & $0.2065(37.5 \%)$ & $-0.0393(21.1 \%)$ & $0.0000(100.0 \%)$ & $0.0000(100.0 \%)$ \\
\hline & Exact & -0.0655 & 0.0271 & 4.3931 & -1.7428 & 0.3306 & -0.0498 & 0.6401 & 0.0762 \\
\hline \multirow[t]{6}{*}{10} & $\begin{array}{l}\text { SinRefc- } \\
11 \mathrm{p}\end{array}$ & $-0.0583(0.1 \%)$ & $0.0211(0.0 \%)$ & $2.7754(0.0 \%)$ & $-1.6624(0.3 \%)$ & $0.2286(0.4 \%)$ & $-0.0412(0.1 \%)$ & $0.6921(0.3 \%)$ & $0.0612(2.1 \%)$ \\
\hline & Sinc & $-0.0556(4.6 \%)$ & $0.0204(2.9 \%)$ & $2.7092(2.4 \%)$ & $-1.6940(2.2 \%)$ & $0.2226(2.2 \%)$ & $-0.0398(3.4 \%)$ & $0.4190(39.3 \%)$ & $0.0579(3.4 \%)$ \\
\hline & $\operatorname{Sin}$ & $-0.0566(2.8 \%)$ & $0.0208(1.3 \%)$ & $2.7367(1.4 \%)$ & $-1.6954(2.3 \%)$ & $0.2250(1.2 \%)$ & $-0.0404(1.8 \%)$ & $0.6190(10.3 \%)$ & $0.0787(31.3 \%)$ \\
\hline & FSDT & $-0.0564(3.2 \%)$ & $0.0210(0.0 \%)$ & $2.7889(0.5 \%)$ & $-1.6357(1.3 \%)$ & $0.2250(1.2 \%)$ & $-0.0403(2.1 \%)$ & $0.4370(36.7 \%)$ & $0.0532(11.2 \%)$ \\
\hline & CLT & $-0.0566(2.9 \%)$ & $0.0196(6.8 \%)$ & $2.4628(11.3 \%)$ & $-1.6411(1.0 \%)$ & $0.2065(9.3 \%)$ & $-0.0393(4.6 \%)$ & $0.0000(100.0 \%)$ & $0.0000(100.0 \%)$ \\
\hline & Exact & -0.0583 & 0.0211 & 2.7760 & -1.6569 & 0.2277 & -0.0412 & 0.6903 & 0.0600 \\
\hline \multirow[t]{6}{*}{20} & $\begin{array}{l}\text { SinRefc- } \\
11 p\end{array}$ & $-0.0570(0.0 \%)$ & $0.0200(0.0 \%)$ & $2.5410(0.0 \%)$ & $-1.6469(0.1 \%)$ & $0.2120(0.0 \%)$ & $-0.0398(0.0 \%)$ & $0.6996(0.1 \%)$ & $0.0584(2.2 \%)$ \\
\hline & Sinc & $-0.0563(1.2 \%)$ & $0.0198(0.8 \%)$ & $2.5248(0.7 \%)$ & $-1.6544(0.6 \%)$ & $0.2106(0.6 \%)$ & $-0.0394(0.9 \%)$ & $0.4214(39.7 \%)$ & $0.0566(1.0 \%)$ \\
\hline & $\operatorname{Sin}$ & $-0.0566(0.7 \%)$ & $0.0199(0.4 \%)$ & $2.5315(0.4 \%)$ & $-1.6547(0.6 \%)$ & $0.2112(0.3 \%)$ & $-0.0396(0.5 \%)$ & $0.6217(11.1 \%)$ & $0.0761(33.2 \%)$ \\
\hline & FSDT & $-0.0566(0.8 \%)$ & $0.0200(0.0 \%)$ & $2.5444(0.1 \%)$ & $-1.6397(0.3 \%)$ & $0.2113(0.3 \%)$ & $-0.0396(0.5 \%)$ & $0.4378(37.4 \%)$ & $0.0509(11.0 \%)$ \\
\hline & CLT & $-0.0566(0.8 \%)$ & $0.0196(1.8 \%)$ & $2.4628(3.1 \%)$ & $-1.6411(0.2 \%)$ & $0.2065(2.5 \%)$ & $-0.0393(1.2 \%)$ & $0.0000(100.0 \%)$ & $0.0000(100.0 \%)$ \\
\hline & Exact & -0.0570 & 0.0200 & 2.5413 & -1.6450 & 0.2119 & -0.0398 & 0.6991 & 0.0572 \\
\hline \multirow[t]{6}{*}{40} & $\begin{array}{l}\text { SinRefc- } \\
11 \mathrm{p}\end{array}$ & $-0.0567(0.0 \%)$ & $0.0197(0.0 \%)$ & $2.4822(0.0 \%)$ & $-1.6431(0.1 \%)$ & $0.2077(0.1 \%)$ & $-0.0394(0.0 \%)$ & $0.7016(0.0 \%)$ & $0.0577(2.2 \%)$ \\
\hline & Sinc & $-0.0565(0.3 \%)$ & $0.0197(0.2 \%)$ & $2.4783(0.2 \%)$ & $-1.6444(0.1 \%)$ & $0.2075(0.2 \%)$ & $-0.0394(0.2 \%)$ & $0.4220(39.8 \%)$ & $0.0563(0.3 \%)$ \\
\hline & $\operatorname{Sin}$ & $-0.0566(0.2 \%)$ & $0.0197(0.1 \%)$ & $2.4800(0.1 \%)$ & $-1.6445(0.1 \%)$ & $0.2077(0.1 \%)$ & $-0.0394(0.1 \%)$ & $0.6224(11.3 \%)$ & $0.0755(33.7 \%)$ \\
\hline & FSDT & $-0.0566(0.2 \%)$ & $0.0197(0.0 \%)$ & $2.4833(0.0 \%)$ & $-1.6407(0.1 \%)$ & $0.2077(0.1 \%)$ & $-0.0394(0.1 \%)$ & $0.4380(37.6 \%)$ & $0.0503(10.9 \%)$ \\
\hline & CLT & $-0.0566(0.2 \%)$ & $0.0196(0.5 \%)$ & $2.4628(0.8 \%)$ & $-1.6411(0.1 \%)$ & $0.2065(0.7 \%)$ & $-0.0393(0.3 \%)$ & $0.0000(100.0 \%)$ & $0.0000(100.0 \%)$ \\
\hline & Exact & -0.0567 & 0.0197 & 2.4824 & -1.6421 & 0.2079 & -0.0394 & 0.7014 & 0.0564 \\
\hline \multirow[t]{6}{*}{100} & $\begin{array}{l}\text { SinRefc- } \\
11 \mathrm{p}\end{array}$ & $-0.0566(0.0 \%)$ & $0.0196(0.0 \%)$ & $2.4657(0.0 \%)$ & $-1.6421(0.0 \%)$ & $0.2065(0.1 \%)$ & $-0.0393(0.0 \%)$ & $0.7022(0.0 \%)$ & $0.0574(2.2 \%)$ \\
\hline & Sinc & $-0.0566(0.0 \%)$ & $0.0196(0.0 \%)$ & $2.4653(0.0 \%)$ & $-1.6416(0.0 \%)$ & $0.2067(0.0 \%)$ & $-0.0393(0.0 \%)$ & $0.4222(39.9 \%)$ & $0.0562(0.1 \%)$ \\
\hline & Sin & $-0.0566(0.0 \%)$ & $0.0196(0.0 \%)$ & $2.4656(0.0 \%)$ & $-1.6417(0.0 \%)$ & $0.2067(0.0 \%)$ & $-0.0393(0.0 \%)$ & $0.6226(11.3 \%)$ & $0.0753(33.9 \%)$ \\
\hline & FSDT & $-0.0566(0.0 \%)$ & $0.0196(0.0 \%)$ & $2.4661(0.0 \%)$ & $-1.6411(0.0 \%)$ & $0.2067(0.0 \%)$ & $-0.0393(0.0 \%)$ & $0.4380(37.6 \%)$ & $0.0501(10.9 \%)$ \\
\hline & CLT & $-0.0566(0.0 \%)$ & $0.0196(0.1 \%)$ & $2.4628(0.1 \%)$ & $-1.6411(0.0 \%)$ & $0.2065(0.1 \%)$ & $-0.0393(0.1 \%)$ & $0.0000(100.0 \%)$ & $0.0000(100.0 \%)$ \\
\hline & Exact & -0.0566 & 0.0196 & 2.4659 & -1.6413 & 0.2067 & -0.0393 & 0.7020 & 0.0562 \\
\hline
\end{tabular}
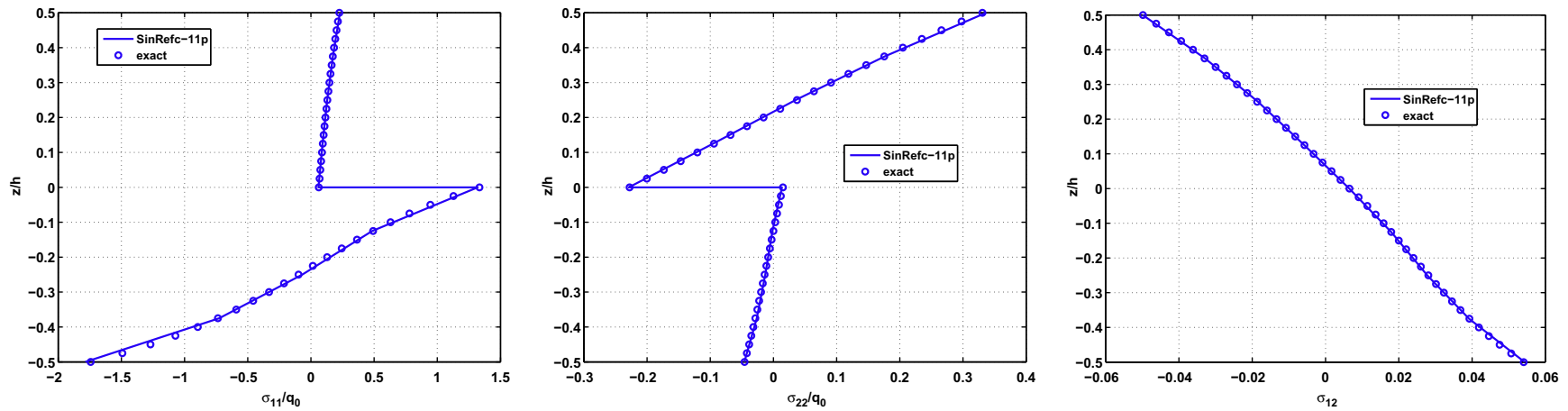

Fig. 7. Distribution of $\bar{\sigma}_{11}$ (left), $\bar{\sigma}_{22}$ (middle) and $\bar{\sigma}_{12}$ (right) along the thickness $-S=4-2$ layers - SinRefc-11p.

For $S \geqslant 20$, all the models give good results only for displacements and in-plane stresses. The improvement of the accuracy of the results for the SinRefc-11p is particularly significant for the transverses shear stresses regardless of the span-to-thickness ratio. The results computed from the constitutive law are in good agree- ment with the exact solution. The maximum error rate is less than $2.2 \%$ for $S \geqslant 4$.

The variation of normalized in-plane, transverse shear and normal stresses, and in-plane and transverse displacements through the thickness $(S=4)$ are shown in Figs. 7-9 for further comparison. 

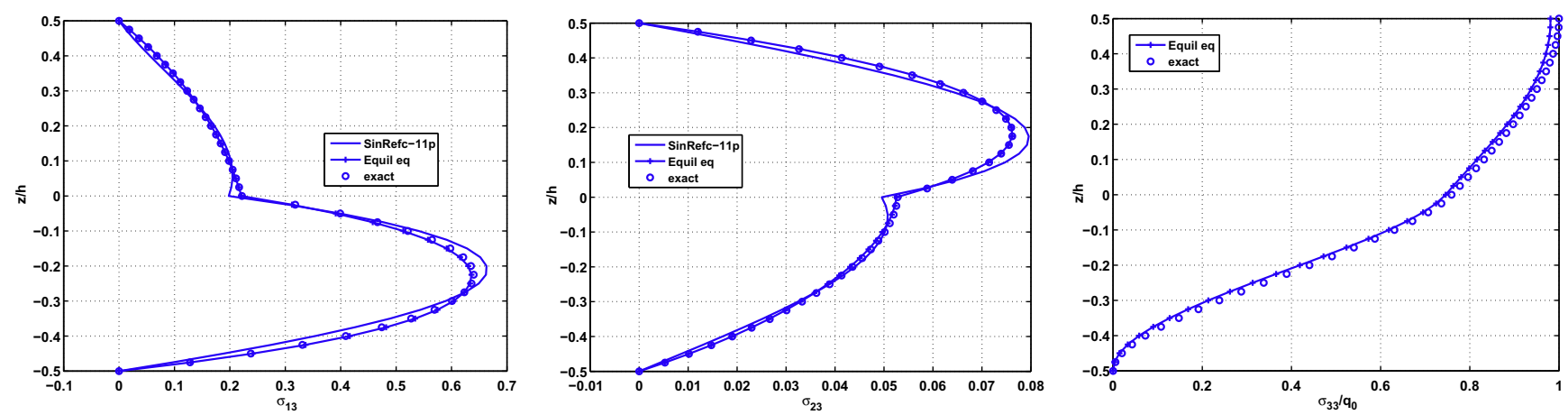

Fig. 8. distribution of $\bar{\sigma}_{13}$ (left), $\bar{\sigma}_{23}$ (middle) and $\bar{\sigma}_{33}$ (right) along the thickness $-S=4-2$ layers - SinRefc-11p.
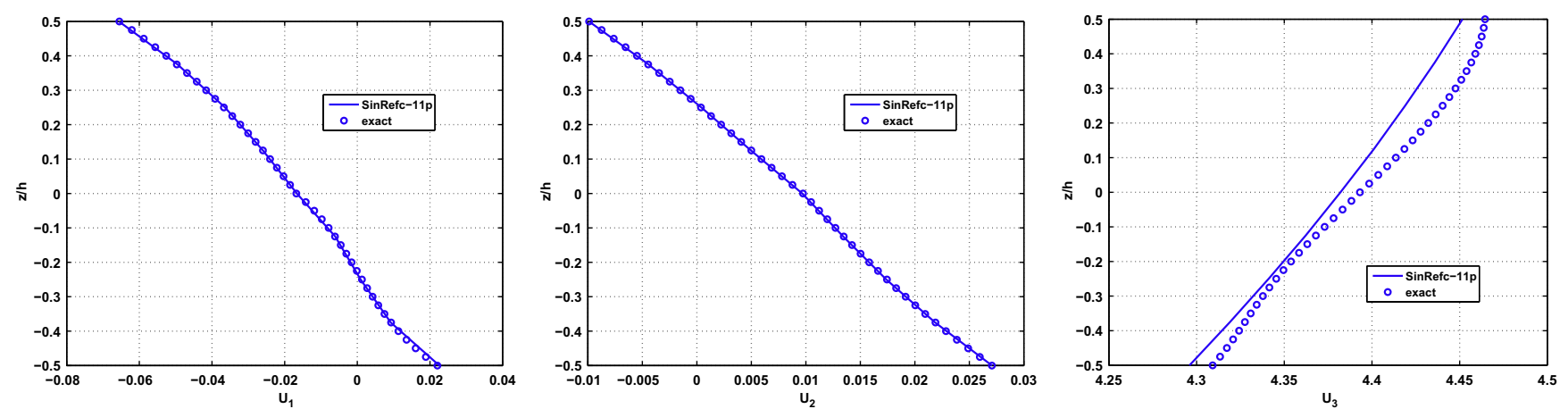

Fig. 9. distribution of $\bar{U}_{1}$ (left), $\bar{U}_{2}$ (middle), $\bar{U}_{3}$ (right) along the thickness $-S=4-2$ layers - SinRefc-11p.

It is seen from these figures that the new element performs very well for thick plate, which is not the case for the other models (see Table 3).

As far as the three-layer case is concerned, the results are shown in Table 4 for a rectangular plate. The SinRefc- 11 p model yields again the more accurate results. The maximum error rate remains less than $1.2 \%$ for both the displacements and the stresses for $S \geqslant 4$. The main improvement is about the transverse shear stresses. For the displacements, this improvement increases when $S$ decreases. CLT and FSDT models fail to predict good results for $S \leqslant 10$ and $S \leqslant 40$ respectively, and the out-of-plane stresses are never well-estimated.

A comparison is also given in Table 5 with three well-established models issued from the Carrera's unified formulation. In this table, $\mathrm{H}$ refers to the use of Hooke's law and E Eq means that the transverse shear stresses are calculated by integrating the equilibrium equations. We notice that the present model is better than an ESL model with 12 unknown functions (ED3). The accuracy of the SinRefc-11p and the second-order LW approach is similar, but with a different computational cost. The importance of the zig-zag effect, via Murakami's function for EDZ3 or using our approach, is highlighted. Note that the process to evaluate the transverse shear stresses is different between the four approaches, and our FE needs no post-processing calculation.

Figs. 10-12 show the distribution of the displacements and the stresses through the thickness for $S=4$. These results show that the present element yields very satisfactory distributions.

For a square plate with three layers (Table 6), the same comments can be made. The maximum error rate of the present FE is $1 \%$ for $S \geqslant 4$ proving the accuracy of the approach.

\subsection{Bending analysis of a sandwich plate}

A sandwich plate is now analyzed. The test is described as follows:
Geometry: square sandwich plate with length-to-thickness ratios from $S=2$ to $S=100$. The thickness of each face sheet is $\frac{h}{10}$. Boundary conditions: simply-supported plate subjected to bisinusoidal load $q\left(x_{1}, x_{2}\right)=q_{0} \sin \frac{\pi x_{1}}{a} \sin \frac{\pi x_{2}}{b}$.

Material properties: the material of the face sheet is the same as in 4.1 .

The core material is transversely isotropic with respect to $z$ and is characterized by:

$E_{x x}=E_{y y}=0.04 \mathrm{GPa}, \quad E_{z z}=0.5 \mathrm{GPa}, \quad G_{x z}=G_{y z}=0.06 \mathrm{GPa}$, $G_{x y}=0.016 \mathrm{GPa}, v_{x z}=v_{y z}=0.02, v_{x y}=0.25$.

Mesh: $N=8$ is used for the quarter of the plate.

Results: displacements and stresses are made non-dimensional according to

$$
\begin{aligned}
& \bar{U}_{\alpha}=U_{\alpha} \frac{E_{L}}{q_{0} h S^{3}} \text { for }\left\{\begin{array}{l}
U_{1}(0, b / 2, z) \\
U_{2}(a / 2,0, z)
\end{array}\right. \\
& \bar{U}_{3}=U_{3}(a / 2, b / 2, z) \frac{100 E_{L}}{q_{0} h S^{4}}, \\
& \bar{\sigma}_{\alpha \beta}=\sigma_{\alpha \beta} \frac{1}{q_{0} S^{2}} \text { for }\left\{\begin{array}{l}
\sigma_{11}(a / 2, a / 2, z), \\
\sigma_{12}(0,0, z),
\end{array}, \sigma_{22}(a / 2, a / 2, z),\right. \\
& \bar{\sigma}_{\alpha 3}=\sigma_{\alpha 3} \frac{1}{q_{0} S} \text { for }\left\{\begin{array}{l}
\sigma_{13}(0, b / 2, z), \\
\sigma_{23}(a / 2,0, z),
\end{array}\right. \\
& \bar{\sigma}_{33}=\sigma_{33}(a / 2, b / 2, z) \frac{1}{q_{0}} .
\end{aligned}
$$

Reference values are the three-dimensional exact elasticity results given by Pagano [22].

The results are summarized in Table 7 and the distribution of the mechanical quantities through the thickness are shown in Figs. $13-15$. The SinRefc- $11 \mathrm{p}$ is also suitable to model very thick to thin sandwich structures. For $S \geqslant 4$, the error rate remains less than $3.3 \%$ for the stresses and $0.6 \%$ for the displacements. The 
Table 4

Results for simply supported rectangular plate $-b=3 a-3$ layers.

\begin{tabular}{|c|c|c|c|c|c|c|c|c|c|}
\hline$S$ & & $\bar{U}_{1}(h / 2)$ & $\bar{U}_{2}(-h / 2)$ & $\bar{U}_{3}(0)$ & $\bar{\sigma}_{11}(h / 2)$ & $\bar{\sigma}_{22}(-h / 6)$ & $\bar{\sigma}_{12}(h / 2)$ & $\bar{\sigma}_{13}(0)$ & $\bar{\sigma}_{23}(0)$ \\
\hline \multirow[t]{6}{*}{2} & SinRefc-11p & $-0.0284(9.0 \%)$ & $0.0285(1.8 \%)$ & $8.1500(0.2 \%)$ & $2.3241(9.0 \%)$ & $-0.2705(1.0 \%)$ & $-0.0567(0.6 \%)$ & $0.2564(0.3 \%)$ & $0.0670(0.3 \%)$ \\
\hline & Sinc & $-0.0280(7.8 \%)$ & $\begin{array}{l}0.0226 \\
(19.6 \%)\end{array}$ & $\begin{array}{l}6.4696 \\
(20.8 \%)\end{array}$ & $2.2129(3.7 \%)$ & $\begin{array}{l}-0.1893 \\
(29.3 \%)\end{array}$ & $\begin{array}{l}-0.0501 \\
(11.1 \%)\end{array}$ & $0.2531(1.6 \%)$ & $0.0469(29.7 \%)$ \\
\hline & $\operatorname{Sin}$ & $-0.0269(3.4 \%)$ & $0.0297(6.0 \%)$ & 7.7796 (4.7\%) & $2.1256(0.4 \%)$ & $\begin{array}{l}-0.2067 \\
(22.8 \%)\end{array}$ & $-0.0608(7.9 \%)$ & $0.2395(6.8 \%)$ & $0.0690(3.4 \%)$ \\
\hline & FSDT & $\begin{array}{l}-0.0075 \\
(71.3 \%)\end{array}$ & $\begin{array}{l}0.0249 \\
(11.3 \%)\end{array}$ & $7.8184(4.3 \%)$ & $\begin{array}{l}0.5940 \\
(72.2 \%)\end{array}$ & $\begin{array}{l}-0.2195 \\
(18.0 \%)\end{array}$ & $\begin{array}{l}-0.0430 \\
(23.8 \%)\end{array}$ & $0.1538(40.2 \%)$ & $0.0536(19.8 \%)$ \\
\hline & CLT & $\begin{array}{l}-0.0079 \\
(69.6 \%)\end{array}$ & $\begin{array}{l}0.0026 \\
(90.6 \%)\end{array}$ & $\begin{array}{l}0.5034 \\
(93.8 \%)\end{array}$ & $\begin{array}{l}0.6232 \\
(70.8 \%)\end{array}$ & $\begin{array}{l}-0.0251 \\
(90.6 \%)\end{array}$ & $\begin{array}{l}-0.0083 \\
(85.3 \%)\end{array}$ & $\begin{array}{l}-0.0000 \\
(100.0 \%)\end{array}$ & $\begin{array}{l}-0.0000 \\
(100.0 \%)\end{array}$ \\
\hline & exact & -0.0260 & 0.0281 & 8.1659 & 2.1331 & -0.2677 & -0.0564 & 0.2571 & 0.0668 \\
\hline \multirow[t]{6}{*}{4} & SinRefc-11p & $-0.0143(0.6 \%)$ & $0.0133(0.4 \%)$ & $2.8227(0.1 \%)$ & $1.1541(0.9 \%)$ & $-0.1182(0.9 \%)$ & $-0.0268(0.2 \%)$ & $0.3508(0.1 \%)$ & $0.0333(0.1 \%)$ \\
\hline & Sinc & $-0.0154(7.9 \%)$ & $0.0125(5.6 \%)$ & $2.7298(3.2 \%)$ & $1.2138(6.1 \%)$ & $\begin{array}{l}-0.1062 \\
(10.9 \%)\end{array}$ & $-0.0277(2.9 \%)$ & $0.3784(7.8 \%)$ & $0.0299(10.2 \%)$ \\
\hline & $\operatorname{Sin}$ & $-0.0135(5.1 \%)$ & $0.0125(5.1 \%)$ & $2.6658(5.5 \%)$ & $1.0672(6.7 \%)$ & $\begin{array}{l}-0.1034 \\
(13.3 \%)\end{array}$ & $-0.0268(0.4 \%)$ & $0.2851(18.8 \%)$ & $0.0355(6.3 \%)$ \\
\hline & FSDT & $\begin{array}{l}-0.0078 \\
(45.6 \%)\end{array}$ & $\begin{array}{l}0.0104 \\
(21.0 \%)\end{array}$ & $\begin{array}{l}2.3625 \\
(16.3 \%)\end{array}$ & $\begin{array}{l}0.6130 \\
(46.4 \%)\end{array}$ & $\begin{array}{l}-0.0934 \\
(21.7 \%)\end{array}$ & $\begin{array}{l}-0.0205 \\
(23.9 \%)\end{array}$ & $0.1566(55.4 \%)$ & $0.0257(23.1 \%)$ \\
\hline & CLT & $\begin{array}{l}-0.0079 \\
(44.5 \%)\end{array}$ & $\begin{array}{l}0.0026 \\
(80.1 \%)\end{array}$ & $\begin{array}{l}0.5034 \\
(82.2 \%)\end{array}$ & $\begin{array}{l}0.6233 \\
(45.5 \%)\end{array}$ & $\begin{array}{l}-0.0251 \\
(78.9 \%)\end{array}$ & $\begin{array}{l}-0.0083 \\
(69.2 \%)\end{array}$ & $\begin{array}{l}-0.0000 \\
(100.0 \%)\end{array}$ & $\begin{array}{l}-0.0000 \\
(100.0 \%)\end{array}$ \\
\hline & exact & -0.0142 & 0.0132 & 2.8211 & 1.1443 & -0.1193 & -0.0269 & 0.3511 & 0.0334 \\
\hline \multirow[t]{6}{*}{10} & SinRefc-11p & $-0.0092(0.0 \%)$ & $0.0047(0.0 \%)$ & $0.9190(0.0 \%)$ & $0.7269(0.1 \%)$ & $-0.0430(1.2 \%)$ & $-0.0120(0.0 \%)$ & $0.4201(0.0 \%)$ & $0.0152(0.1 \%)$ \\
\hline & Sinc & $-0.0093(1.4 \%)$ & $0.0047(1.8 \%)$ & $0.9183(0.1 \%)$ & $0.7331(1.0 \%)$ & $-0.0418(3.8 \%)$ & $-0.0122(1.8 \%)$ & $0.4410(5.0 \%)$ & $0.0151(1.1 \%)$ \\
\hline & Sin & $-0.0089(3.4 \%)$ & $0.0044(6.4 \%)$ & $0.8698(5.3 \%)$ & $0.6983(3.8 \%)$ & $-0.0401(7.8 \%)$ & $-0.0116(3.0 \%)$ & $0.3021(28.1 \%)$ & $0.0172(13.1 \%)$ \\
\hline & FSDT & $\begin{array}{l}-0.0079 \\
(14.0 \%)\end{array}$ & $\begin{array}{l}0.0040 \\
(14.8 \%)\end{array}$ & $\begin{array}{l}0.8030 \\
(12.6 \%)\end{array}$ & $\begin{array}{l}0.6214 \\
(14.4 \%)\end{array}$ & $\begin{array}{l}-0.0375 \\
(13.9 \%)\end{array}$ & $\begin{array}{l}-0.0105 \\
(12.5 \%)\end{array}$ & $0.1578(62.4 \%)$ & $0.0133(12.8 \%)$ \\
\hline & CLT & $\begin{array}{l}-0.0079 \\
(13.7 \%)\end{array}$ & $\begin{array}{l}0.0026 \\
(44.5 \%)\end{array}$ & $\begin{array}{l}0.5034 \\
(45.2 \%)\end{array}$ & $\begin{array}{l}0.6233 \\
(14.1 \%)\end{array}$ & $\begin{array}{l}-0.0251 \\
(42.2 \%)\end{array}$ & $\begin{array}{l}-0.0083 \\
(30.9 \%)\end{array}$ & $\begin{array}{l}-0.0000 \\
(100.0 \%)\end{array}$ & $\begin{array}{l}-0.0000 \\
(100.0 \%)\end{array}$ \\
\hline & Exact & -0.0092 & 0.0047 & 0.9189 & 0.7260 & -0.0435 & -0.0120 & 0.4201 & 0.0152 \\
\hline \multirow[t]{6}{*}{20} & SinRefc-11p & $-0.0082(0.0 \%)$ & $0.0032(0.0 \%)$ & $0.6096(0.0 \%)$ & $0.6502(0.0 \%)$ & $-0.0296(0.8 \%)$ & $-0.0092(0.0 \%)$ & $0.4344(0.0 \%)$ & $0.0120(0.1 \%)$ \\
\hline & Sinc & $-0.0083(0.3 \%)$ & $0.0032(0.7 \%)$ & $0.6096(0.0 \%)$ & $0.6514(0.2 \%)$ & $-0.0295(1.4 \%)$ & $-0.0093(0.6 \%)$ & $0.4517(4.0 \%)$ & $0.0122(1.8 \%)$ \\
\hline & $\operatorname{Sin}$ & $-0.0081(1.1 \%)$ & $0.0031(2.7 \%)$ & $0.5958(2.3 \%)$ & $0.6422(1.2 \%)$ & $-0.0290(3.0 \%)$ & $-0.0091(1.2 \%)$ & $0.3047(29.8 \%)$ & $0.0141(18.2 \%)$ \\
\hline & FSDT & $-0.0079(4.1 \%)$ & $0.0030(5.9 \%)$ & $0.5784(5.1 \%)$ & $0.6228(4.2 \%)$ & $-0.0283(5.4 \%)$ & $-0.0088(4.3 \%)$ & $0.1580(63.6 \%)$ & $0.0113(5.8 \%)$ \\
\hline & CLT & $-0.0079(4.0 \%)$ & $\begin{array}{l}0.0026 \\
(17.2 \%)\end{array}$ & $\begin{array}{l}0.5034 \\
(17.4 \%)\end{array}$ & $0.6232(4.1 \%)$ & $\begin{array}{l}-0.0251 \\
(15.9 \%)\end{array}$ & $\begin{array}{l}-0.0083 \\
(10.4 \%)\end{array}$ & $\begin{array}{l}-0.0000 \\
(100.0 \%)\end{array}$ & $\begin{array}{l}-0.0000 \\
(100.0 \%)\end{array}$ \\
\hline & Exact & -0.0082 & 0.0032 & 0.6095 & 0.6500 & -0.0299 & -0.0092 & 0.4344 & 0.0119 \\
\hline \multirow[t]{6}{*}{40} & SinRefc-11p & $-0.0080(0.0 \%)$ & $0.0028(0.0 \%)$ & $0.5301(0.0 \%)$ & $0.6301(0.0 \%)$ & $-0.0262(0.6 \%)$ & $-0.0085(0.0 \%)$ & $0.4382(0.0 \%)$ & $0.0111(0.1 \%)$ \\
\hline & Sinc & $-0.0080(0.1 \%)$ & $0.0028(0.2 \%)$ & $0.5301(0.0 \%)$ & $0.6303(0.0 \%)$ & $-0.0262(0.4 \%)$ & $-0.0085(0.2 \%)$ & $0.4545(3.7 \%)$ & $0.0114(2.8 \%)$ \\
\hline & $\operatorname{Sin}$ & $-0.0080(0.3 \%)$ & $0.0028(0.8 \%)$ & $0.5265(0.7 \%)$ & $0.6280(0.3 \%)$ & $-0.0261(0.9 \%)$ & $-0.0085(0.3 \%)$ & $0.3054(30.3 \%)$ & $0.0133(20.1 \%)$ \\
\hline & FSDT & $-0.0079(1.1 \%)$ & $0.0027(1.7 \%)$ & $0.5221(1.5 \%)$ & $0.6231(1.1 \%)$ & $-0.0259(1.6 \%)$ & $-0.0084(1.2 \%)$ & $0.1581(63.9 \%)$ & $0.0107(3.1 \%)$ \\
\hline & CLT & $-0.0079(1.0 \%)$ & $0.0026(5.0 \%)$ & $0.5034(5.0 \%)$ & $0.6233(1.1 \%)$ & $-0.0251(4.6 \%)$ & $-0.0083(2.8 \%)$ & $\begin{array}{l}-0.0000 \\
(100.0 \%)\end{array}$ & $\begin{array}{l}-0.0000 \\
(100.0 \%)\end{array}$ \\
\hline & Exact & -0.0080 & 0.0028 & 0.5301 & 0.6300 & -0.0263 & -0.0085 & 0.4382 & 0.0111 \\
\hline \multirow[t]{6}{*}{100} & SinRefc-11p & $-0.0079(0.0 \%)$ & $0.0027(0.0 \%)$ & $0.5077(0.0 \%)$ & $0.6244(0.0 \%)$ & $-0.0252(0.6 \%)$ & $-0.0083(0.0 \%)$ & $0.4394(0.0 \%)$ & $0.0109(0.2 \%)$ \\
\hline & Sinc & $-0.0079(0.0 \%)$ & $0.0027(0.0 \%)$ & $0.5077(0.0 \%)$ & $0.6244(0.0 \%)$ & $-0.0253(0.1 \%)$ & $-0.0083(0.0 \%)$ & $0.4553(3.6 \%)$ & $0.0112(3.1 \%)$ \\
\hline & $\operatorname{Sin}$ & $-0.0079(0.0 \%)$ & $0.0027(0.1 \%)$ & $0.5071(0.1 \%)$ & $0.6240(0.1 \%)$ & $-0.0253(0.2 \%)$ & $-0.0083(0.1 \%)$ & $0.3056(30.4 \%)$ & $0.0131(20.7 \%)$ \\
\hline & FSDT & $-0.0079(0.2 \%)$ & $0.0027(0.3 \%)$ & $0.5064(0.3 \%)$ & $0.6232(0.2 \%)$ & $-0.0253(0.3 \%)$ & $-0.0083(0.2 \%)$ & $0.1581(64.0 \%)$ & $0.0106(2.3 \%)$ \\
\hline & CLT & $-0.0079(0.2 \%)$ & $0.0026(0.8 \%)$ & $0.5034(0.8 \%)$ & $0.6233(0.2 \%)$ & $-0.0251(0.8 \%)$ & $-0.0083(0.5 \%)$ & $\begin{array}{l}-0.0000 \\
(100.0 \%)\end{array}$ & $\begin{array}{l}-0.0000 \\
(100.0 \%)\end{array}$ \\
\hline & Exact & -0.0079 & 0.0027 & 0.5077 & 0.6244 & -0.0253 & -0.0083 & 0.4393 & 0.0108 \\
\hline
\end{tabular}

results of the Sinus model with continuity are better than those of the original Sin model. As expected, the validity of the classical models (FSDT, CLT) is limited to the thin plate only for displacements and in-plane stresses.

A comparison with the three models issued from CUF is given in Table 8. The refined Sinus model is more accurate and efficient (lower computational cost than the CUF models presented in this table), including with respect to the LW approach with a 2nd order expansion.

\subsection{Thermo-mechanical results}

Only the present FE is now evaluated for the thermo-mechanical coupling as the transverse normal stress is needed for a correct modeling of this coupling [20]. The test is described below:

Geometry: square plate with length-to-thickness ratios from $S=4$ to $S=100$. All layers have the same thickness.
Boundary conditions: simply-supported plate subjected to a bi-sinusoidal temperature field $T\left(x_{1}, x_{2}, z\right)=T_{0} \frac{2 z}{h} \sin \frac{\pi x_{1}}{a} \sin \frac{\pi x_{2}}{b}$ (linear temperature profile across the thickness).

Material properties: composite cross-ply plate $\left(0^{\circ} / 90^{\circ} / 0^{\circ}\right)$ and $\left(0^{\circ} / 90^{\circ}\right)$ with the same properties of 4.1 and $\alpha_{T}=1125 \alpha_{L}$, where $\alpha_{L}, \alpha_{T}$ are the thermal expansion coefficients in the fiber and transverse direction, respectively.

Mesh: $N=8$ is used for the quarter of the plate.

Results: displacements and stresses are made non-dimensional according to

$$
\begin{aligned}
& \bar{U}_{\alpha}=U_{\alpha} \frac{1}{\alpha_{L} T_{0} h S} \text { for }\left\{\begin{array}{l}
U_{1}(0, b / 2, z) \\
U_{2}(a / 2,0, z)
\end{array} \quad \bar{U}_{3}=U_{3}(a / 2, b / 2, z) \frac{1}{\alpha_{L} T_{0} h S^{2}},\right. \\
& \bar{\sigma}_{\alpha \beta}=\sigma_{\alpha \beta} \frac{1}{E_{T} \alpha_{L} T_{0}} \text { for }\left\{\begin{array}{l}
\sigma_{11}(a / 2, a / 2, z), \sigma_{22}(a / 2, a / 2, z), \sigma_{12}(0,0, z), \\
\sigma_{13}(0, b / 2, z), \sigma_{23}(a / 2,0, z), \sigma_{33}(a / 2, b / 2, z) .
\end{array}\right.
\end{aligned}
$$

Reference values are the three-dimensional exact elasticity results given by Bhaskar et al. [23]. 
Table 5

Results for simply supported rectangular plate $-b=3 a-3$ layers.

\begin{tabular}{|c|c|c|c|c|c|c|c|c|}
\hline \multirow[t]{2}{*}{$S$} & \multirow[t]{2}{*}{$\mathrm{Nb}$ fcts } & \multicolumn{3}{|l|}{$\bar{U}_{3}(0)$} & & \multicolumn{3}{|l|}{$\bar{\sigma}_{13}(0)$} \\
\hline & & 4 & 10 & 20 & & 4 & 10 & 20 \\
\hline Exact & 2.8211 & 0.9189 & 0.6095 & & & 0.3511 & 0.4201 & 0.4344 \\
\hline SinRefc-11p & 11 & $2.8227(0.1 \%)$ & $0.9190(0.0 \%)$ & $0.6096(0.0 \%)$ & $\mathrm{H}$ & $0.3508(0.1 \%)$ & $0.4201(0.0 \%)$ & $0.4344(0.0 \%)$ \\
\hline ED3 & 12 & $2.627(6.9 \%)$ & $0.867(5.6 \%)$ & $0.595(2.4 \%)$ & E Eq & $0.376(7 \%)$ & $0.427(1.6 \%)$ & $0.436(0.4 \%)$ \\
\hline EDZ3 & 12 & $2.811(0.4 \%)$ & $0.919(0.0 \%)$ & $0.610(0.0 \%)$ & $\mathrm{E} \mathrm{Eq}$ & $0.347(1.2 \%)$ & $0.420(0.0 \%)$ & $0.434(0.0 \%)$ \\
\hline LD2 & 21 & $2.798(0.8 \%)$ & $0.918(0.1 \%)$ & $0.610(0.0 \%)$ & $\mathrm{E}$ Eq & $0.347(1.2 \%)$ & $0.420(0.0 \%)$ & $0.434(0.1 \%)$ \\
\hline
\end{tabular}
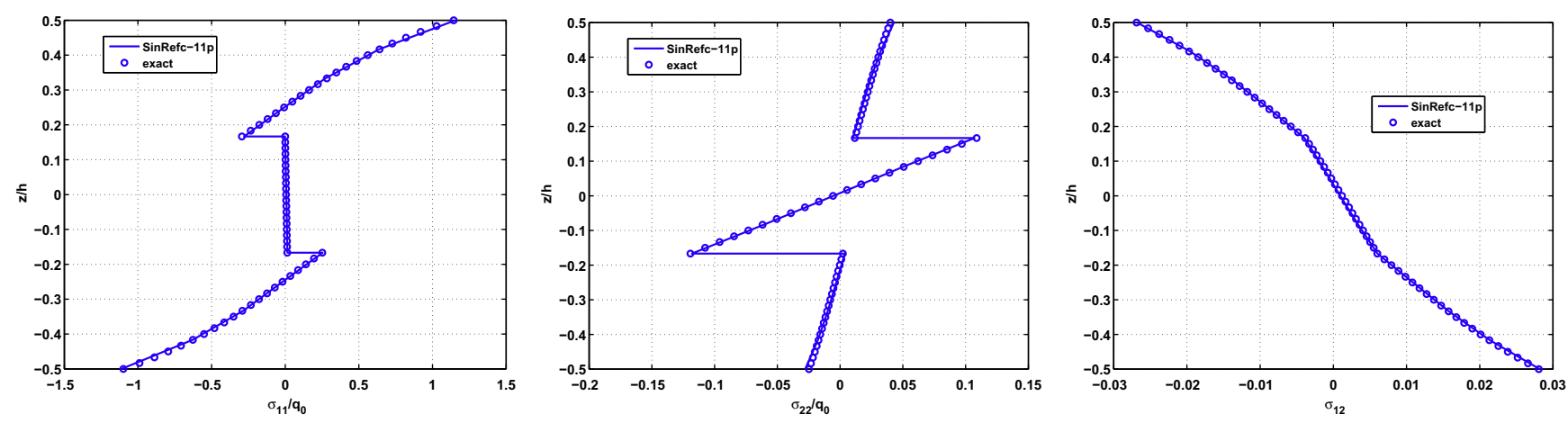

Fig. 10. distribution of $\bar{\sigma}_{11}$ (left), $\bar{\sigma}_{22}$ (middle) and $\bar{\sigma}_{12}$ (right) along the thickness $-S=4-3$ layers - SinRefc-11p.
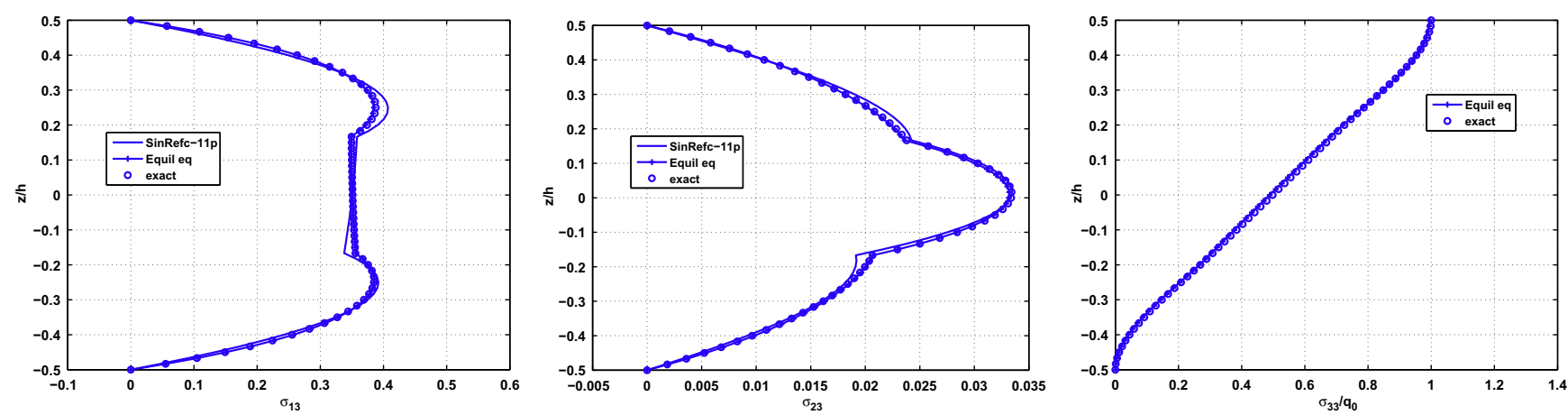

Fig. 11. distribution of $\bar{\sigma}_{13}$ (left), $\bar{\sigma}_{23}$ (middle), and $\bar{\sigma}_{33}$ (right) along the thickness $-S=4-3$ layers - SinRefc-11p.
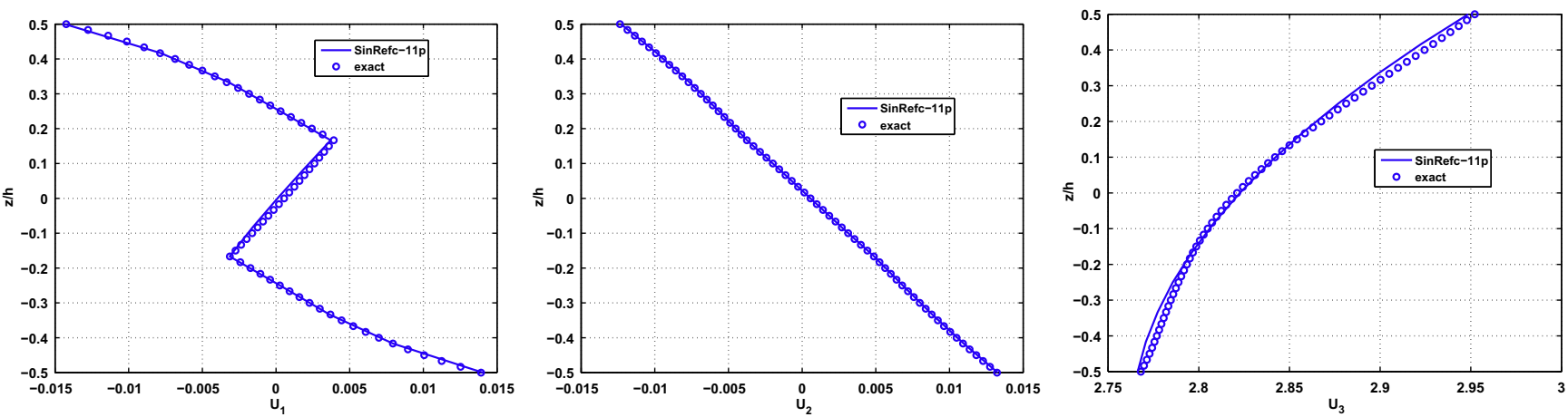

Fig. 12. distribution of $\bar{U}_{1}$ (left), $\bar{U}_{2}$ (middle), $\bar{U}_{3}$ (right) along the thickness $-S=4-3$ layers - SinRefc-11p 
Table 6

Results for simply supported square plate $-b=a-3$ layers.

\begin{tabular}{|c|c|c|c|c|c|c|c|c|c|}
\hline$S$ & & $\bar{U}_{1}(h / 2)$ & $\bar{U}_{2}(-h / 2)$ & $\bar{U}_{3}(0)$ & $\bar{\sigma}_{11}(h / 2)$ & $\bar{\sigma}_{22}(-h / 6)$ & $\bar{\sigma}_{12}(h / 2)$ & $\bar{\sigma}_{13}(0)$ & $\bar{\sigma}_{23}(0)$ \\
\hline \multirow[t]{6}{*}{2} & SinRefc-11p & $\begin{array}{l}-0.0188 \\
(11.8 \%)\end{array}$ & $0.0330(0.3 \%)$ & $5.1117(0.3 \%)$ & $\begin{array}{l}1.6013 \\
(11.5 \%)\end{array}$ & $-0.7692(3.6 \%)$ & $-0.0894(4.0 \%)$ & $0.1636(0.2 \%)$ & $0.2655(2.5 \%)$ \\
\hline & Sinc & $\begin{array}{l}-0.0188 \\
(11.3 \%)\end{array}$ & $\begin{array}{l}0.0282 \\
(14.7 \%)\end{array}$ & $\begin{array}{l}4.4271 \\
(13.1 \%)\end{array}$ & $1.5001(4.5 \%)$ & $-0.7972(7.4 \%)$ & $\begin{array}{l}-0.0738 \\
(14.0 \%)\end{array}$ & $0.1746(6.5 \%)$ & $0.1712(33.9 \%)$ \\
\hline & $\operatorname{Sin}$ & $-0.0168(0.1 \%)$ & $\begin{array}{l}0.0410 \\
(23.8 \%)\end{array}$ & $5.0635(0.6 \%)$ & $1.3582(5.4 \%)$ & $\begin{array}{l}-0.5662 \\
(23.7 \%)\end{array}$ & $-0.0908(5.7 \%)$ & $0.1576(3.9 \%)$ & $0.2422(6.5 \%)$ \\
\hline & FSDT & $\begin{array}{l}-0.0043 \\
(74.5 \%)\end{array}$ & $\begin{array}{l}0.0268 \\
(19.1 \%)\end{array}$ & $5.2293(2.6 \%)$ & $\begin{array}{l}0.3597 \\
(75.0 \%)\end{array}$ & $-0.7038(5.2 \%)$ & $\begin{array}{l}-0.0488 \\
(43.2 \%)\end{array}$ & $0.1038(36.7 \%)$ & $0.1846(28.8 \%)$ \\
\hline & CLT & $\begin{array}{l}-0.0068 \\
(59.8 \%)\end{array}$ & $\begin{array}{l}0.0068 \\
(79.5 \%)\end{array}$ & $\begin{array}{l}0.4313 \\
(91.5 \%)\end{array}$ & $\begin{array}{l}0.5387 \\
(62.5 \%)\end{array}$ & $\begin{array}{l}-0.1796 \\
(75.8 \%)\end{array}$ & $\begin{array}{l}-0.0213 \\
(75.2 \%)\end{array}$ & $\begin{array}{l}-0.0000 \\
(100.0 \%)\end{array}$ & $\begin{array}{l}-0.0000 \\
(100.0 \%)\end{array}$ \\
\hline & Exact & -0.0169 & 0.0331 & 5.0954 & 1.4360 & -0.7424 & -0.0859 & 0.1640 & 0.2591 \\
\hline \multirow[t]{6}{*}{4} & SinRefc-11p & $-0.0097(0.5 \%)$ & $0.0228(0.2 \%)$ & $2.0080(0.1 \%)$ & $0.8086(1.0 \%)$ & $-0.5583(0.4 \%)$ & $-0.0511(0.1 \%)$ & $0.2556(0.1 \%)$ & $0.2190(0.8 \%)$ \\
\hline & Sinc & $-0.0107(9.9 \%)$ & $0.0218(4.3 \%)$ & $1.9622(2.2 \%)$ & $0.8560(6.9 \%)$ & $-0.5838(5.0 \%)$ & $-0.0510(0.1 \%)$ & $0.2774(8.4 \%)$ & $0.1494(31.2 \%)$ \\
\hline & $\operatorname{Sin}$ & $-0.0094(3.4 \%)$ & $0.0229(0.6 \%)$ & $1.9345(3.6 \%)$ & $0.7554(5.7 \%)$ & $-0.5033(9.5 \%)$ & $-0.0507(0.7 \%)$ & $0.2113(17.4 \%)$ & $0.1877(13.6 \%)$ \\
\hline & FSDT & $\begin{array}{l}-0.0054 \\
(44.6 \%)\end{array}$ & $\begin{array}{l}0.0181 \\
(20.4 \%)\end{array}$ & $\begin{array}{l}1.7758 \\
(11.5 \%)\end{array}$ & $\begin{array}{l}0.4370 \\
(45.4 \%)\end{array}$ & $\begin{array}{l}-0.4774 \\
(14.2 \%)\end{array}$ & $\begin{array}{l}-0.0369 \\
(27.7 \%)\end{array}$ & $0.1201(53.1 \%)$ & $0.1301(40.1 \%)$ \\
\hline & CLT & $\begin{array}{l}-0.0068 \\
(30.1 \%)\end{array}$ & $\begin{array}{l}0.0068 \\
(70.3 \%)\end{array}$ & $\begin{array}{l}0.4313 \\
(78.5 \%)\end{array}$ & $\begin{array}{l}0.5387 \\
(32.7 \%)\end{array}$ & $\begin{array}{l}-0.1796 \\
(67.7 \%)\end{array}$ & $\begin{array}{l}-0.0213 \\
(58.3 \%)\end{array}$ & $\begin{array}{l}-0.0000 \\
(100.0 \%)\end{array}$ & $\begin{array}{l}-0.0000 \\
(100.0 \%)\end{array}$ \\
\hline & Exact & -0.0097 & 0.0228 & 2.0059 & 0.8008 & -0.5563 & -0.0511 & 0.2559 & 0.2172 \\
\hline \multirow[t]{6}{*}{10} & SinRefc-11p & $-0.0074(0.0 \%)$ & $0.0111(0.0 \%)$ & $0.7531(0.0 \%)$ & $0.5915(0.2 \%)$ & $-0.2880(0.1 \%)$ & $-0.0288(0.0 \%)$ & $0.3573(0.0 \%)$ & $0.1232(0.4 \%)$ \\
\hline & Sinc & $-0.0075(1.7 \%)$ & $0.0110(0.6 \%)$ & $0.7533(0.0 \%)$ & $0.5975(1.2 \%)$ & $-0.2908(0.9 \%)$ & $-0.0290(0.7 \%)$ & $0.3744(4.8 \%)$ & $0.0859(30.0 \%)$ \\
\hline & $\operatorname{Sin}$ & $-0.0072(2.5 \%)$ & $0.0106(4.2 \%)$ & $0.7180(4.6 \%)$ & $0.5727(3.0 \%)$ & $-0.2708(6.0 \%)$ & $-0.0279(3.1 \%)$ & $0.2583(27.7 \%)$ & $0.1059(13.7 \%)$ \\
\hline & FSDT & $\begin{array}{l}-0.0064 \\
(12.6 \%)\end{array}$ & $\begin{array}{l}0.0096 \\
(13.3 \%)\end{array}$ & $\begin{array}{l}0.6693 \\
(11.1 \%)\end{array}$ & $\begin{array}{l}0.5134 \\
(13.1 \%)\end{array}$ & $\begin{array}{l}-0.2536 \\
(12.0 \%)\end{array}$ & $\begin{array}{l}-0.0252 \\
(12.7 \%)\end{array}$ & $0.1363(61.9 \%)$ & $0.0762(37.9 \%)$ \\
\hline & CLT & $-0.0068(7.9 \%)$ & $\begin{array}{l}0.0068 \\
(38.8 \%)\end{array}$ & $\begin{array}{l}0.4313 \\
(42.7 \%)\end{array}$ & $0.5387(8.8 \%)$ & $\begin{array}{l}-0.1796 \\
(37.7 \%)\end{array}$ & $\begin{array}{l}-0.0213 \\
(26.2 \%)\end{array}$ & $\begin{array}{l}-0.0000 \\
(100.0 \%)\end{array}$ & $\begin{array}{l}-0.0000 \\
(100.0 \%)\end{array}$ \\
\hline & Exact & -0.0074 & 0.0111 & 0.7530 & 0.5906 & -0.2882 & -0.0288 & 0.3573 & 0.1228 \\
\hline \multirow[t]{6}{*}{20} & SinRefc-11p & $-0.0069(0.0 \%)$ & $0.0080(0.0 \%)$ & $0.5164(0.0 \%)$ & $0.5526(0.0 \%)$ & $-0.2101(0.0 \%)$ & $-0.0234(0.0 \%)$ & $0.3846(0.0 \%)$ & $0.0941(0.4 \%)$ \\
\hline & Sinc & $-0.0070(0.4 \%)$ & $0.0080(0.1 \%)$ & $0.5166(0.0 \%)$ & $0.5538(0.3 \%)$ & $-0.2105(0.2 \%)$ & $-0.0234(0.2 \%)$ & $0.3991(3.8 \%)$ & $0.0671(28.4 \%)$ \\
\hline & Sin & $-0.0069(0.8 \%)$ & $0.0078(1.9 \%)$ & $0.5057(2.1 \%)$ & $0.5471(1.0 \%)$ & $-0.2049(2.5 \%)$ & $-0.0231(1.3 \%)$ & 0.2697 (29.9\%) & $0.0843(10.2 \%)$ \\
\hline & FSDT & $-0.0067(3.6 \%)$ & $0.0075(5.3 \%)$ & $0.4921(4.7 \%)$ & $0.5318(3.7 \%)$ & $-0.1997(5.0 \%)$ & $-0.0223(4.4 \%)$ & $0.1402(63.6 \%)$ & $0.0632(32.6 \%)$ \\
\hline & CLT & $-0.0068(2.2 \%)$ & $\begin{array}{l}0.0068 \\
(15.0 \%)\end{array}$ & $\begin{array}{l}0.4313 \\
(16.5 \%)\end{array}$ & $0.5387(2.5 \%)$ & $\begin{array}{l}-0.1796 \\
(14.5 \%)\end{array}$ & $-0.0213(8.9 \%)$ & $\begin{array}{l}-0.0000 \\
(100.0 \%)\end{array}$ & $\begin{array}{l}-0.0000 \\
(100.0 \%)\end{array}$ \\
\hline & Exact & -0.0069 & 0.0080 & 0.5164 & 0.5524 & -0.2101 & -0.0234 & 0.3846 & 0.0938 \\
\hline \multirow[t]{6}{*}{40} & SinRefc-11p & $-0.0068(0.0 \%)$ & $0.0071(0.0 \%)$ & $0.4529(0.0 \%)$ & $0.5422(0.0 \%)$ & $-0.1874(0.0 \%)$ & $-0.0218(0.0 \%)$ & $0.3925(0.0 \%)$ & $0.0856(0.4 \%)$ \\
\hline & Sinc & $-0.0068(0.1 \%)$ & $0.0071(0.0 \%)$ & $0.4529(0.0 \%)$ & $0.5425(0.1 \%)$ & $-0.1875(0.0 \%)$ & $-0.0218(0.1 \%)$ & $0.4060(3.5 \%)$ & $0.0617(27.7 \%)$ \\
\hline & Sin & $-0.0068(0.2 \%)$ & $0.0070(0.6 \%)$ & $0.4501(0.6 \%)$ & $0.5408(0.3 \%)$ & $-0.1861(0.7 \%)$ & $-0.0217(0.4 \%)$ & $0.2728(30.5 \%)$ & $0.0781(8.4 \%)$ \\
\hline & FSDT & $-0.0067(0.9 \%)$ & $0.0070(1.6 \%)$ & $0.4466(1.4 \%)$ & $0.5369(1.0 \%)$ & $-0.1847(1.5 \%)$ & $-0.0216(1.2 \%)$ & $0.1413(64.0 \%)$ & $0.0596(30.1 \%)$ \\
\hline & CLT & $-0.0068(0.6 \%)$ & $0.0068(4.3 \%)$ & $0.4313(4.8 \%)$ & $0.5387(0.6 \%)$ & $-0.1796(4.2 \%)$ & $-0.0213(2.4 \%)$ & $\begin{array}{l}-0.0000 \\
(100.0 \%)\end{array}$ & $\begin{array}{l}-0.0000 \\
(100.0 \%)\end{array}$ \\
\hline & Exact & -0.0068 & 0.0071 & 0.4529 & 0.5422 & -0.1874 & -0.0218 & 0.3924 & 0.0853 \\
\hline \multirow[t]{6}{*}{100} & SinRefc-11p & $-0.0068(0.0 \%)$ & $0.0068(0.0 \%)$ & $0.4347(0.0 \%)$ & $0.5393(0.0 \%)$ & $-0.1808(0.0 \%)$ & $-0.0214(0.0 \%)$ & $0.3947(0.0 \%)$ & $0.0831(0.4 \%)$ \\
\hline & Sinc & $-0.0068(0.0 \%)$ & $0.0068(0.0 \%)$ & $0.4347(0.0 \%)$ & $0.5393(0.0 \%)$ & $-0.1808(0.0 \%)$ & $-0.0214(0.0 \%)$ & $0.4081(3.4 \%)$ & $0.0601(27.5 \%)$ \\
\hline & $\operatorname{Sin}$ & $-0.0068(0.0 \%)$ & $0.0068(0.1 \%)$ & $0.4343(0.1 \%)$ & $0.5390(0.0 \%)$ & $-0.1806(0.1 \%)$ & $-0.0214(0.1 \%)$ & $0.2737(30.6 \%)$ & $0.0764(7.8 \%)$ \\
\hline & FSDT & $-0.0068(0.1 \%)$ & $0.0068(0.3 \%)$ & $0.4337(0.2 \%)$ & $0.5384(0.2 \%)$ & $-0.1804(0.2 \%)$ & $-0.0213(0.2 \%)$ & $0.1416(64.1 \%)$ & $0.0586(29.3 \%)$ \\
\hline & CLT & $-0.0068(0.1 \%)$ & $0.0068(0.7 \%)$ & $0.4313(0.8 \%)$ & $0.5387(0.1 \%)$ & $-0.1796(0.7 \%)$ & $-0.0213(0.4 \%)$ & $\begin{array}{l}-0.0000 \\
(100.0 \%)\end{array}$ & $\begin{array}{l}-0.0000 \\
(100.0 \%)\end{array}$ \\
\hline & Exact & -0.0068 & 0.0068 & 0.4347 & 0.5393 & -0.1808 & -0.0214 & 0.3947 & 0.0828 \\
\hline
\end{tabular}

Table 7

Results for simply supported sandwich square plate $-b=a$.

\begin{tabular}{|c|c|c|c|c|c|c|c|c|c|}
\hline$S$ & & $\bar{U}_{1}(-h / 2)$ & $\bar{U}_{2}(-h / 2)$ & $\bar{U}_{3}(0)$ & $\bar{\sigma}_{11}(h / 2)$ & $\bar{\sigma}_{22}(-h / 2)$ & $\bar{\sigma}_{12}(-h / 2)$ & $\bar{\sigma}_{13}(0)$ & $\bar{\sigma}_{23}(0)$ \\
\hline \multirow[t]{6}{*}{2} & SinRefc-11p & $0.0325(0.2 \%)$ & $0.1196(2.8 \%)$ & $22.2375(0.6 \%)$ & $3.2375(1.2 \%)$ & $-0.4135(5.5 \%)$ & $0.2389(2.2 \%)$ & $0.1841(0.4 \%)$ & $0.1404(0.4 \%)$ \\
\hline & Sinc & $\begin{array}{l}0.0385 \\
(18.2 \%)\end{array}$ & $0.1209(3.9 \%)$ & $22.2987(0.9 \%)$ & $3.1227(4.7 \%)$ & $-0.4109(4.9 \%)$ & $0.2503(7.1 \%)$ & $0.1996(8.0 \%)$ & $0.1562(11.7 \%)$ \\
\hline & $\operatorname{Sin}$ & $0.0336(3.3 \%)$ & $0.1168(0.5 \%)$ & $21.2125(4.0 \%)$ & $\begin{array}{l}2.7375 \\
(16.5 \%)\end{array}$ & $-0.3944(0.6 \%)$ & $0.2363(1.1 \%)$ & $0.2259(22.2 \%)$ & $0.1631(16.6 \%)$ \\
\hline & FSDT & $\begin{array}{l}0.0087 \\
(73.4 \%)\end{array}$ & $\begin{array}{l}0.0717 \\
(38.3 \%)\end{array}$ & $\begin{array}{l}14.9287 \\
(32.5 \%)\end{array}$ & $\begin{array}{l}0.7378 \\
(77.5 \%)\end{array}$ & $\begin{array}{l}-0.2328 \\
(40.6 \%)\end{array}$ & $\begin{array}{l}0.1263 \\
(46.0 \%)\end{array}$ & 0.0903 (51.1\%) & $0.0651(53.5 \%)$ \\
\hline & CLT & $\begin{array}{l}0.0138 \\
(57.6 \%)\end{array}$ & $\begin{array}{l}0.0138 \\
(88.1 \%)\end{array}$ & $0.8782(96.0 \%)$ & $\begin{array}{l}1.0970 \\
(66.5 \%)\end{array}$ & $\begin{array}{l}-0.0543 \\
(86.1 \%)\end{array}$ & $\begin{array}{l}0.0433 \\
(81.5 \%)\end{array}$ & $\begin{array}{l}-0.0000 \\
(100.0 \%)\end{array}$ & $\begin{array}{l}-0.0000 \\
(100.0 \%)\end{array}$ \\
\hline & Exact & 0.0325 & 0.1163 & 22.1029 & 3.2781 & -0.3919 & 0.2338 & 0.1848 & 0.1399 \\
\hline \multirow[t]{5}{*}{4} & SinRefc-11p & $0.0183(0.6 \%)$ & $0.0760(0.2 \%)$ & $7.5883(0.1 \%)$ & $1.5532(0.2 \%)$ & $-0.2608(3.0 \%)$ & $0.1481(0.0 \%)$ & $0.2377(0.4 \%)$ & $0.1079(0.6 \%)$ \\
\hline & Sinc & $0.0190(3.2 \%)$ & $0.0756(0.3 \%)$ & $7.6098(0.2 \%)$ & $1.5589(0.2 \%)$ & $-0.2530(0.1 \%)$ & $0.1486(0.4 \%)$ & $0.2573(7.8 \%)$ & $0.1198(11.7 \%)$ \\
\hline & Sin & $0.0175(5.0 \%)$ & $0.0713(6.0 \%)$ & $7.0928(6.6 \%)$ & $1.4359(7.7 \%)$ & $-0.2382(5.9 \%)$ & $0.1395(5.8 \%)$ & $0.2832(18.6 \%)$ & $0.1211(13.0 \%)$ \\
\hline & FSDT & $\begin{array}{l}0.0109 \\
(41.1 \%)\end{array}$ & $\begin{array}{l}0.0469 \\
(38.1 \%)\end{array}$ & $4.7666(37.3 \%)$ & $\begin{array}{l}0.8918 \\
(42.7 \%)\end{array}$ & $\begin{array}{l}-0.1562 \\
(38.3 \%)\end{array}$ & $\begin{array}{l}0.0907 \\
(38.7 \%)\end{array}$ & $0.1024(57.1 \%)$ & $0.0448(58.2 \%)$ \\
\hline & CLT & 0.0138 & 0.0138 & $0.8782(88.4 \%)$ & 1.0970 & -0.0543 & 0.0433 & -0.0000 & -0.0000 \\
\hline
\end{tabular}


Table 7 (continued)

\begin{tabular}{|c|c|c|c|c|c|c|c|c|c|}
\hline$S$ & & $\bar{U}_{1}(-h / 2)$ & $\bar{U}_{2}(-h / 2)$ & $\bar{U}_{3}(0)$ & $\bar{\sigma}_{11}(h / 2)$ & $\bar{\sigma}_{22}(-h / 2)$ & $\bar{\sigma}_{12}(-h / 2)$ & $\bar{\sigma}_{13}(0)$ & $\bar{\sigma}_{23}(0)$ \\
\hline & & $(25.2 \%)$ & $(81.8 \%)$ & & $(29.5 \%)$ & $(78.6 \%)$ & $(70.7 \%)$ & (100.0\%) & (100.0\%) \\
\hline & Exact & 0.0184 & 0.0758 & 7.5962 & 1.5558 & -0.2533 & 0.1480 & 0.2387 & 0.1072 \\
\hline \multirow[t]{6}{*}{10} & SinRefc-11p & $0.0142(0.5 \%)$ & $0.0313(0.1 \%)$ & $2.1946(0.3 \%)$ & $1.1523(0.1 \%)$ & $-0.1131(2.9 \%)$ & $0.0715(0.2 \%)$ & $0.2991(0.2 \%)$ & $0.0532(1.1 \%)$ \\
\hline & Sinc & $0.0144(0.3 \%)$ & $0.0311(0.8 \%)$ & $2.1977(0.1 \%)$ & $1.1555(0.2 \%)$ & $-0.1091(0.7 \%)$ & $0.0713(0.4 \%)$ & $0.3225(7.6 \%)$ & $0.0589(11.9 \%)$ \\
\hline & $\operatorname{Sin}$ & $0.0141(1.5 \%)$ & $0.0293(6.4 \%)$ & $2.0681(6.0 \%)$ & $1.1337(1.7 \%)$ & $-0.1034(5.9 \%)$ & $0.0682(4.8 \%)$ & $0.3465(15.6 \%)$ & $0.0598(13.5 \%)$ \\
\hline & FSDT & $0.0131(8.8 \%)$ & $\begin{array}{l}0.0221 \\
(29.5 \%)\end{array}$ & $1.5604(29.1 \%)$ & $1.0457(9.3 \%)$ & $\begin{array}{l}-0.0798 \\
(27.4 \%)\end{array}$ & $\begin{array}{l}0.0552 \\
(23.0 \%)\end{array}$ & $0.1145(61.8 \%)$ & $0.0245(53.6 \%)$ \\
\hline & CLT & $0.0138(3.6 \%)$ & $\begin{array}{l}0.0138 \\
(55.9 \%)\end{array}$ & $0.8782(60.1 \%)$ & 1.0970 (4.9\%) & $\begin{array}{l}-0.0543 \\
(50.6 \%)\end{array}$ & $\begin{array}{l}0.0433 \\
(39.5 \%)\end{array}$ & $\begin{array}{l}-0.0000 \\
(100.0 \%)\end{array}$ & $\begin{array}{l}-0.0000 \\
(100.0 \%)\end{array}$ \\
\hline & Exact & 0.0143 & 0.0313 & 2.2004 & 1.1531 & -0.1099 & 0.0717 & 0.2998 & 0.0527 \\
\hline \multirow[t]{6}{*}{20} & SinRefc-11p & $0.0139(0.4 \%)$ & $0.0187(0.2 \%)$ & $1.2228(0.3 \%)$ & 1.1087 (0.1\%) & $-0.0722(3.2 \%)$ & $0.0511(0.3 \%)$ & $0.3169(0.2 \%)$ & $0.0365(1.2 \%)$ \\
\hline & Sinc & $0.0139(0.1 \%)$ & $0.0187(0.4 \%)$ & $1.2254(0.1 \%)$ & $1.1104(0.1 \%)$ & $-0.0697(0.4 \%)$ & $0.0512(0.2 \%)$ & $0.3412(7.5 \%)$ & $0.0405(12.3 \%)$ \\
\hline & $\operatorname{Sin}$ & $0.0139(0.4 \%)$ & $0.0181(3.3 \%)$ & $1.1891(3.0 \%)$ & $1.1049(0.4 \%)$ & $-0.0680(2.8 \%)$ & $0.0502(2.0 \%)$ & $0.3640(14.7 \%)$ & $0.0421(16.8 \%)$ \\
\hline & FSDT & $0.0136(2.2 \%)$ & $\begin{array}{l}0.0160 \\
(14.4 \%)\end{array}$ & $1.0524(14.2 \%)$ & $1.0831(2.4 \%)$ & $\begin{array}{l}-0.0612 \\
(12.5 \%)\end{array}$ & $0.0466(9.2 \%)$ & $0.1174(63.0 \%)$ & $0.0195(45.9 \%)$ \\
\hline & CLT & $0.0138(0.8 \%)$ & $\begin{array}{l}0.0138 \\
(26.4 \%)\end{array}$ & $0.8782(28.4 \%)$ & 1.0970 (1.2\%) & $\begin{array}{l}-0.0543 \\
(22.4 \%)\end{array}$ & $\begin{array}{l}0.0433 \\
(15.5 \%)\end{array}$ & $\begin{array}{l}-0.0000 \\
(100.0 \%)\end{array}$ & $\begin{array}{l}-0.0000 \\
(100.0 \%)\end{array}$ \\
\hline & Exact & 0.0139 & 0.0187 & 1.2264 & 1.1098 & -0.0699 & 0.0513 & 0.3174 & 0.0361 \\
\hline \multirow[t]{6}{*}{40} & SinRefc-11p & $0.0138(0.3 \%)$ & $0.0150(0.3 \%)$ & $0.9635(0.3 \%)$ & $1.0990(0.1 \%)$ & $-0.0603(3.3 \%)$ & $0.0452(0.3 \%)$ & $0.3220(0.1 \%)$ & $0.0316(1.3 \%)$ \\
\hline & Sinc & $0.0138(0.0 \%)$ & $0.0150(0.1 \%)$ & $0.9662(0.0 \%)$ & $1.1002(0.0 \%)$ & $-0.0583(0.1 \%)$ & $0.0454(0.1 \%)$ & $0.3467(7.5 \%)$ & $0.0351(12.5 \%)$ \\
\hline & $\operatorname{Sin}$ & $0.0138(0.1 \%)$ & 0.0149 (1.1\%) & $0.9569(1.0 \%)$ & $1.0989(0.1 \%)$ & $-0.0578(0.9 \%)$ & $0.0451(0.6 \%)$ & $0.3690(14.4 \%)$ & $0.0370(18.7 \%)$ \\
\hline & FSDT & $0.0137(0.6 \%)$ & $0.0144(4.7 \%)$ & $0.9220(4.6 \%)$ & $1.0934(0.6 \%)$ & $-0.0561(3.9 \%)$ & $0.0442(2.7 \%)$ & $0.1182(63.3 \%)$ & $0.0182(41.8 \%)$ \\
\hline & CLT & $0.0138(0.2 \%)$ & $0.0138(8.5 \%)$ & $0.8782(9.1 \%)$ & $1.0970(0.3 \%)$ & $-0.0543(6.9 \%)$ & $0.0433(4.5 \%)$ & $\begin{array}{l}-0.0000 \\
(100.0 \%)\end{array}$ & $\begin{array}{l}-0.0000 \\
(100.0 \%)\end{array}$ \\
\hline & Exact & 0.0138 & 0.0151 & 0.9665 & 1.1001 & -0.0583 & 0.0454 & 0.3225 & 0.0312 \\
\hline \multirow[t]{6}{*}{100} & SinRefc-11p & $0.0138(0.3 \%)$ & $0.0140(0.3 \%)$ & $0.8895(0.3 \%)$ & $1.0964(0.1 \%)$ & $-0.0568(3.3 \%)$ & $0.0435(0.3 \%)$ & $0.3236(0.1 \%)$ & $0.0301(1.3 \%)$ \\
\hline & Sinc & $0.0138(0.0 \%)$ & $0.0140(0.0 \%)$ & $0.8923(0.0 \%)$ & $1.0975(0.0 \%)$ & $-0.0549(0.0 \%)$ & $0.0437(0.0 \%)$ & $0.3483(7.5 \%)$ & $0.0335(12.6 \%)$ \\
\hline & $\operatorname{Sin}$ & $0.0138(0.0 \%)$ & $0.0140(0.2 \%)$ & $0.8908(0.2 \%)$ & $1.0973(0.0 \%)$ & $-0.0549(0.2 \%)$ & $0.0436(0.1 \%)$ & $0.3705(14.4 \%)$ & $0.0355(19.4 \%)$ \\
\hline & FSDT & $0.0138(0.1 \%)$ & $0.0139(0.8 \%)$ & $0.8852(0.8 \%)$ & $1.0964(0.1 \%)$ & $-0.0546(0.7 \%)$ & $0.0435(0.5 \%)$ & $0.1185(63.4 \%)$ & $0.0178(40.3 \%)$ \\
\hline & CLT & $0.0138(0.0 \%)$ & $0.0138(1.5 \%)$ & $0.8782(1.6 \%)$ & $1.0970(0.0 \%)$ & $-0.0543(1.2 \%)$ & $0.0433(0.8 \%)$ & $\begin{array}{l}-0.0000 \\
(100.0 \%)\end{array}$ & $\begin{array}{l}-0.0000 \\
(100.0 \%)\end{array}$ \\
\hline & Exact & 0.0138 & 0.0140 & 0.8924 & 1.0975 & -0.0550 & 0.0437 & 0.3240 & 0.0297 \\
\hline
\end{tabular}

Table 8

Results for simply supported sandwich square plate.

\begin{tabular}{|c|c|c|c|c|c|}
\hline$S$ & & $\mathrm{Nb}$ fcts & $\bar{\sigma}_{11}(h / 2)$ & $\bar{\sigma}_{13}(0)$ & \\
\hline \multirow[t]{5}{*}{2} & SinRefc-11p & 11 & 3.2375 (1.2\%) & $0.1841(0.4 \%)$ & $\mathrm{H}$ \\
\hline & ED3 & 12 & $3.0752(6.2 \%)$ & - & \\
\hline & EDZ3 & 12 & $3.1623(3.5 \%)$ & $0.18301^{\mathrm{a}}(0.9 \%)$ & E Eq \\
\hline & LD2 & 21 & $3.2259(3.2 \%)$ & $0.17834(3.5 \%)$ & $\mathrm{E} \mathrm{Eq}$ \\
\hline & Exact & - & 3.2781 & 0.1848 & \\
\hline \multirow[t]{5}{*}{4} & SinRefc-11p & 11 & $1.5532(0.2 \%)$ & $0.2377(0.4 \%)$ & $\mathrm{H}$ \\
\hline & ED3 & 12 & - & - & \\
\hline & EDZ3 & 12 & - & $0.23751^{\mathrm{a}}(0.5 \%)$ & $\mathrm{E} \mathrm{Eq}$ \\
\hline & LD2 & 21 & - & $0.22778(4.5 \%)$ & $\mathrm{E} \mathrm{Eq}$ \\
\hline & Exact & - & 1.5558 & 0.2387 & \\
\hline \multirow[t]{5}{*}{10} & SinRefc-11p & 11 & $1.1523(0.1 \%)$ & $0.2991(0.2 \%)$ & $\mathrm{H}$ \\
\hline & ED3 & 12 & $1.1452(0.7 \%)$ & - & \\
\hline & EDZ3 & 12 & $1.1484(0.4 \%)$ & $0.29905^{\mathrm{a}}(0.2 \%)$ & $\mathrm{E}$ Eq \\
\hline & LD2 & 21 & $1.1322(1.8 \%)$ & $0.28019(6.5 \%)$ & $\mathrm{E} \mathrm{Eq}$ \\
\hline & Exact & - & 1.1531 & 0.2998 & \\
\hline \multirow[t]{5}{*}{20} & SinRefc-11p & 11 & $1.1087(0.1 \%)$ & $0.3169(0.2 \%)$ & $\mathrm{H}$ \\
\hline & ED3 & 12 & - & - & \\
\hline & EDZ3 & 12 & - & $0.31678^{\mathrm{a}}(0.2 \%)$ & $\mathrm{E}$ Eq \\
\hline & LD2 & 21 & - & $0.29595(6.7 \%)$ & $\mathrm{E} \mathrm{Eq}$ \\
\hline & Exact & - & 1.1098 & 0.3174 & \\
\hline \multirow[t]{5}{*}{50} & SinRefc-11p & 11 & $1.0979(0.1 \%)$ & $0.3227(0.1 \%)$ & $\mathrm{H}$ \\
\hline & ED3 & 12 & $1.0706(2.6 \%)$ & - & \\
\hline & EDZ3 & 12 & $1.0712(2.5 \%)$ & $0.32261^{\mathrm{a}}(0.1 \%)$ & $\mathrm{E}$ Eq \\
\hline & LD2 & 21 & $1.0785(1.9 \%)$ & $0.30177(6.6 \%)$ & $\mathrm{E}$ Eq \\
\hline & Exact & - & 1.0990 & 0.3231 & \\
\hline
\end{tabular}

\footnotetext{
a Analytical closed-form solution.
} 

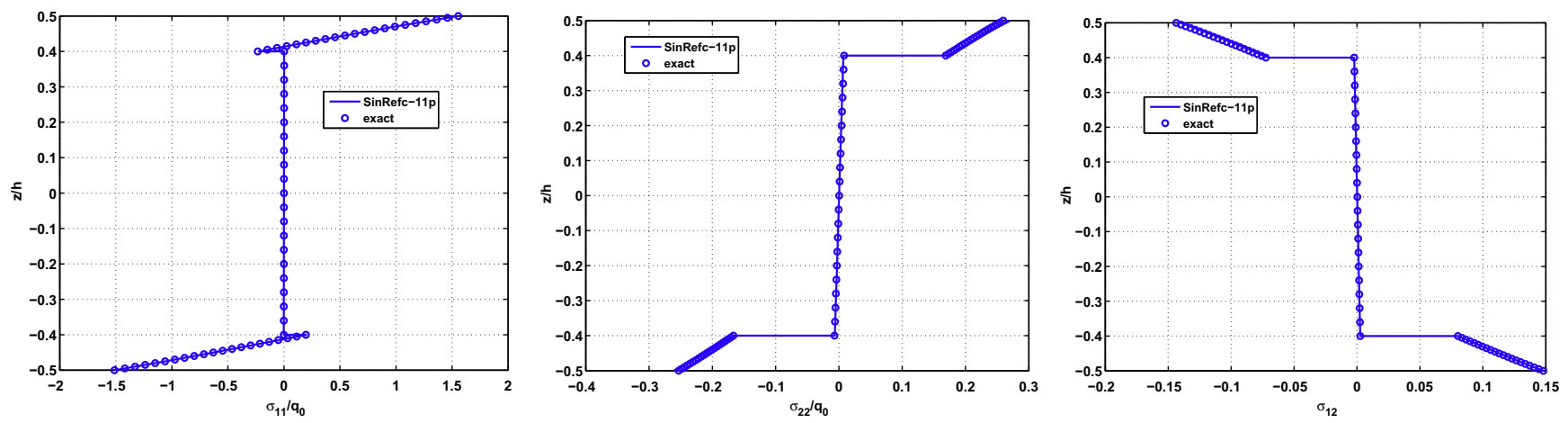

Fig. 13. distribution of $\bar{\sigma}_{11}$ (left), $\bar{\sigma}_{22}$ (middle) and $\bar{\sigma}_{12}$ (right) along the thickness $-S=4-$ sandwich - SinRefc-11p.
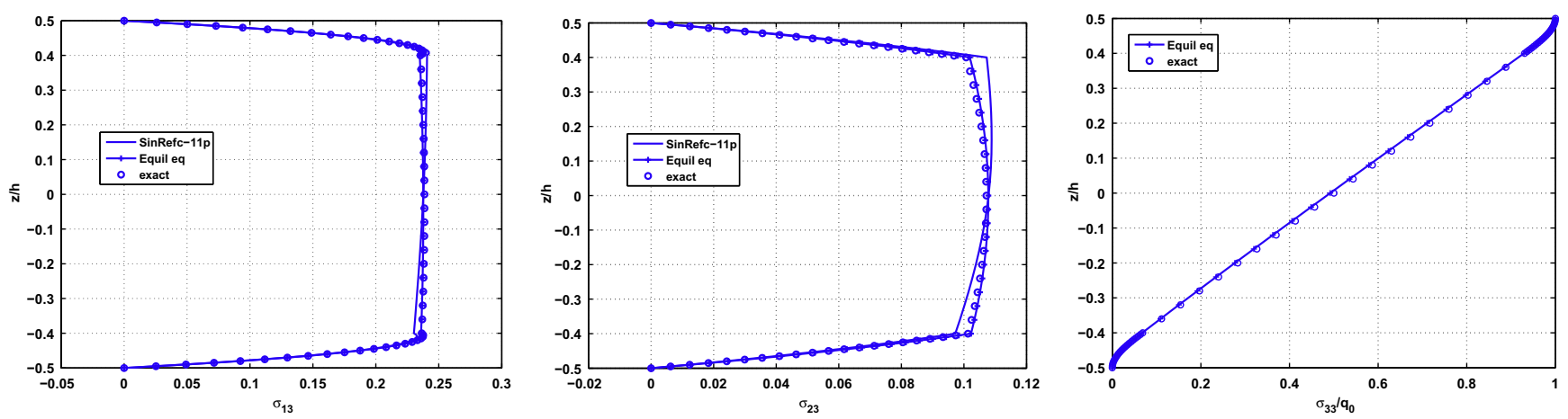

Fig. 14. Distribution of $\bar{\sigma}_{13}$ (left), $\bar{\sigma}_{23}$ (middle) and $\bar{\sigma}_{33}$ (right) along the thickness $-\mathrm{S}=4$ - sandwich - SinRefc-11p.
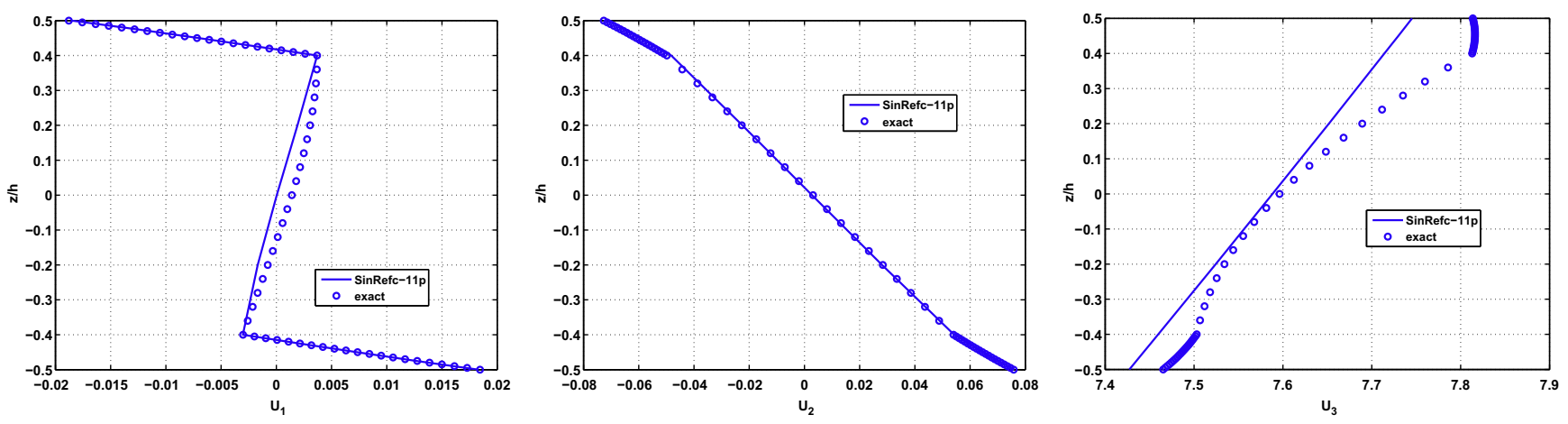

Fig. 15. Distribution of $\bar{U}_{1}$ (left), $\bar{U}_{2}$ (middle), $\bar{U}_{3}$ (right) along the thickness $-S=4$ - sandwich - SinRefc-11p.

Table 9

Results for simply-supported square plate - two layers $\left(0^{\circ} / 90^{\circ}\right)$ - thermo-mechanical $-b=a$.

\begin{tabular}{|c|c|c|c|c|c|c|c|c|c|}
\hline$S$ & Model & $\bar{u}(h / 2)$ & $\bar{v}(-h / 2)$ & $\bar{w}(0)$ & $\bar{\sigma}_{11}(-h / 2)$ & $\bar{\sigma}_{22}(h / 2)$ & $\bar{\sigma}_{12}(h / 2)$ & $\bar{\sigma}_{13} \max$ & $\bar{\sigma}_{23} \max$ \\
\hline \multirow[t]{3}{*}{4} & SinRefc-11p & -123.7700 & 123.7700 & 31.8975 & -1459.0000 & 1459.0000 & -227.7200 & 110.2700 & 110.2700 \\
\hline & Error & $0.2 \%$ & $0.2 \%$ & $0.4 \%$ & $3.0 \%$ & $3.0 \%$ & $0.6 \%$ & $0.3 \%$ & $0.3 \%$ \\
\hline & Exact & -123.5019 & 123.5019 & 32.0251 & -1416.6715 & 1416.6715 & -226.4439 & 110.5875 & 110.5875 \\
\hline \multirow[t]{3}{*}{10} & SinRefc-11p & -94.1320 & 94.1320 & 34.7980 & -1610.8000 & 1610.8000 & -184.6300 & 57.5410 & 57.5410 \\
\hline & Error & $0.0 \%$ & $0.0 \%$ & $0.0 \%$ & $0.4 \%$ & $0.4 \%$ & $0.1 \%$ & $1.3 \%$ & $1.3 \%$ \\
\hline & Exact & -94.0877 & 94.0877 & 34.8032 & -1605.0925 & 1605.0925 & -184.4612 & 58.2761 & 58.2761 \\
\hline \multirow[t]{3}{*}{100} & SinRefc-11p & -86.6050 & 86.6050 & 35.2400 & -1666.8000 & 1666.8000 & -174.0300 & 6.1086 & 6.1087 \\
\hline & Error & $0.0 \%$ & $0.0 \%$ & $0.0 \%$ & $0.1 \%$ & $0.1 \%$ & $0.0 \%$ & $1.7 \%$ & $1.7 \%$ \\
\hline & Exact & -86.6112 & 86.6112 & 35.2424 & -1665.8188 & 1665.8188 & -174.0461 & 6.2142 & 6.2142 \\
\hline
\end{tabular}


Table 10

Results for simply-supported square plate - three layers $\left(0^{\circ} / 90^{\circ} / 0^{\circ}\right)$ - thermo-mechanical $-b=a$.

\begin{tabular}{|c|c|c|c|c|c|c|c|c|c|c|c|}
\hline$S$ & Model & $\bar{u}(h / 2)$ & $\bar{v}(-h / 2)$ & $\bar{w}(h / 2)$ & $\bar{\sigma}_{11}(h / 2)$ & $\bar{\sigma}_{22}(h / 2)$ & $\bar{\sigma}_{12}(h / 2)$ & $\bar{\sigma}_{13}(0)$ & $\bar{\sigma}_{13}(h / 6)$ & $\bar{\sigma}_{23}(0)$ & $\bar{\sigma}_{23}(h / 6)$ \\
\hline 4 & $\begin{array}{l}\text { SinRefc-11p } \\
\text { Error } \\
\text { Exact }\end{array}$ & $\begin{array}{l}-18.2670 \\
0.9 \% \\
-18.1083\end{array}$ & $\begin{array}{l}81.8300 \\
0.0 \% \\
81.8293\end{array}$ & $\begin{array}{l}42.6475 \\
0.1 \% \\
42.6863\end{array}$ & $\begin{array}{l}1198.8000 \\
1.3 \% \\
1183.2018\end{array}$ & $\begin{array}{l}-853.4100 \\
0.3 \% \\
-856.0937\end{array}$ & $\begin{array}{l}-157.2300 \\
0.2 \% \\
-156.9817\end{array}$ & $\begin{array}{l}61.9790 \\
0.2 \% \\
62.1240\end{array}$ & $\begin{array}{l}83.0810 \\
2.0 \% \\
84.8143\end{array}$ & $\begin{array}{l}-47.0930 \\
2.2 \% \\
-48.1399\end{array}$ & $\begin{array}{l}-129.4100 \\
0.5 \% \\
-128.7034\end{array}$ \\
\hline 10 & $\begin{array}{l}\text { SinRefc-11p } \\
\text { Error } \\
\text { Exact }\end{array}$ & $\begin{array}{l}-16.6200 \\
0.0 \% \\
-16.6144\end{array}$ & $\begin{array}{l}31.9520 \\
0.0 \% \\
31.9517\end{array}$ & $\begin{array}{l}17.3900 \\
0.0 \% \\
17.3920\end{array}$ & $\begin{array}{l}1027.6000 \\
0.1 \% \\
1026.3029\end{array}$ & $\begin{array}{l}-1013.7000 \\
0.1 \% \\
-1014.3577\end{array}$ & $\begin{array}{l}-76.2930 \\
0.0 \% \\
-76.2875\end{array}$ & $\begin{array}{l}51.6000 \\
0.0 \% \\
51.6185\end{array}$ & $\begin{array}{l}60.3690 \\
0.3 \% \\
60.5410\end{array}$ & $\begin{array}{l}-49.3640 \\
0.1 \% \\
-49.4115\end{array}$ & $\begin{array}{l}-66.1170 \\
0.2 \% \\
-66.0084\end{array}$ \\
\hline 100 & $\begin{array}{l}\text { SinRefc-11p } \\
\text { Error } \\
\text { Exact }\end{array}$ & $\begin{array}{l}-15.9980 \\
0.0 \% \\
-15.9983\end{array}$ & $\begin{array}{l}16.1700 \\
0.0 \% \\
16.1703\end{array}$ & $\begin{array}{l}10.2600 \\
0.0 \% \\
10.2598\end{array}$ & $\begin{array}{l}965.3700 \\
0.0 \% \\
965.3674\end{array}$ & $\begin{array}{l}-1064.5000 \\
0.0 \% \\
-1064.5458\end{array}$ & $\begin{array}{l}-50.5300 \\
0.0 \% \\
-50.5303\end{array}$ & $\begin{array}{l}6.1868 \\
0.0 \% \\
6.1875\end{array}$ & $\begin{array}{l}7.0733 \\
0.0 \% \\
7.0732\end{array}$ & $\begin{array}{l}-6.1866 \\
0.0 \% \\
-6.1848\end{array}$ & $\begin{array}{l}-7.0776 \\
0.0 \% \\
-7.0797\end{array}$ \\
\hline
\end{tabular}
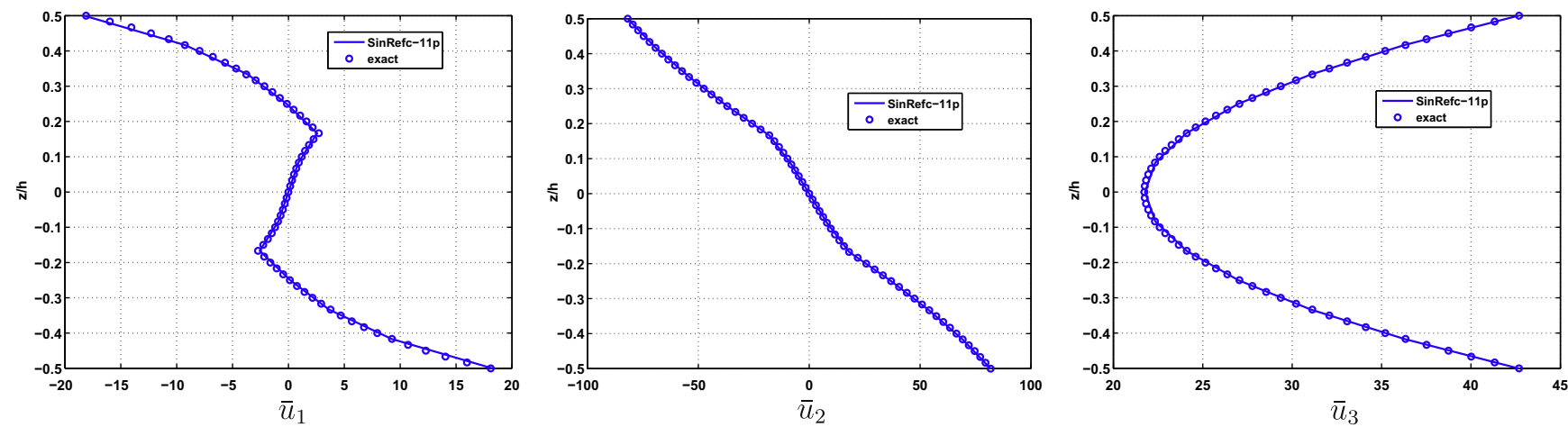

Fig. 16. Distribution of $\bar{u}_{1}$ (left), $\bar{u}_{2}$ (middle) and $\bar{u}_{3}$ (right) along the thickness $-S=4-3$ layers - thermo-mechanical - SinRefc-11p.
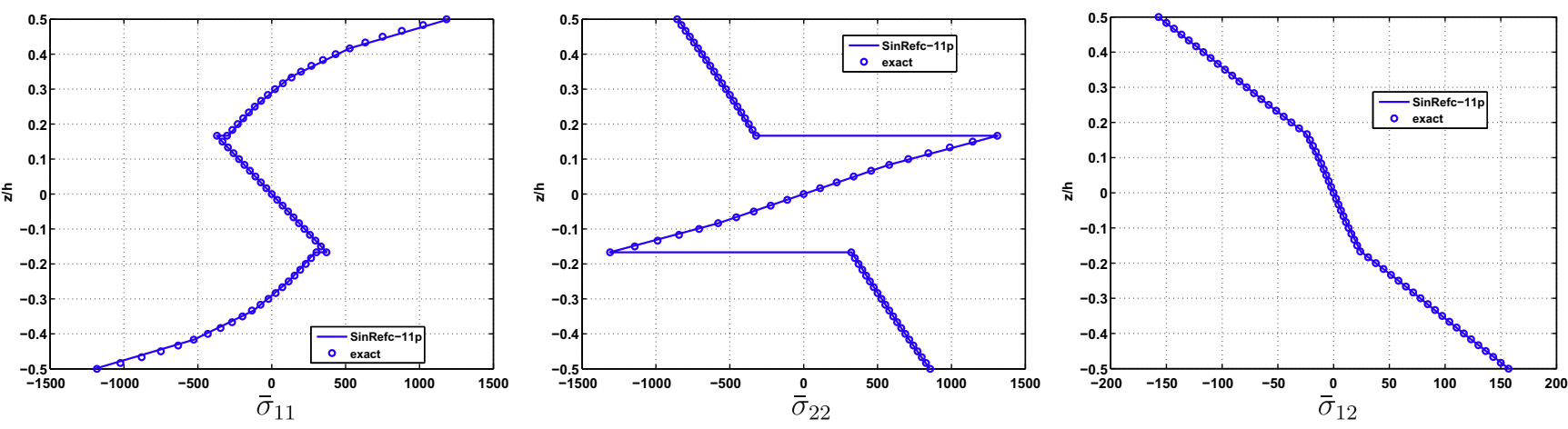

Fig. 17. Distribution of $\bar{\sigma}_{11}$ (left), $\bar{\sigma}_{22}$ (middle) and $\bar{\sigma}_{12}$ (right) along the thickness $-S=4-3$ layers - thermo-mechanical - SinRefc-11p.
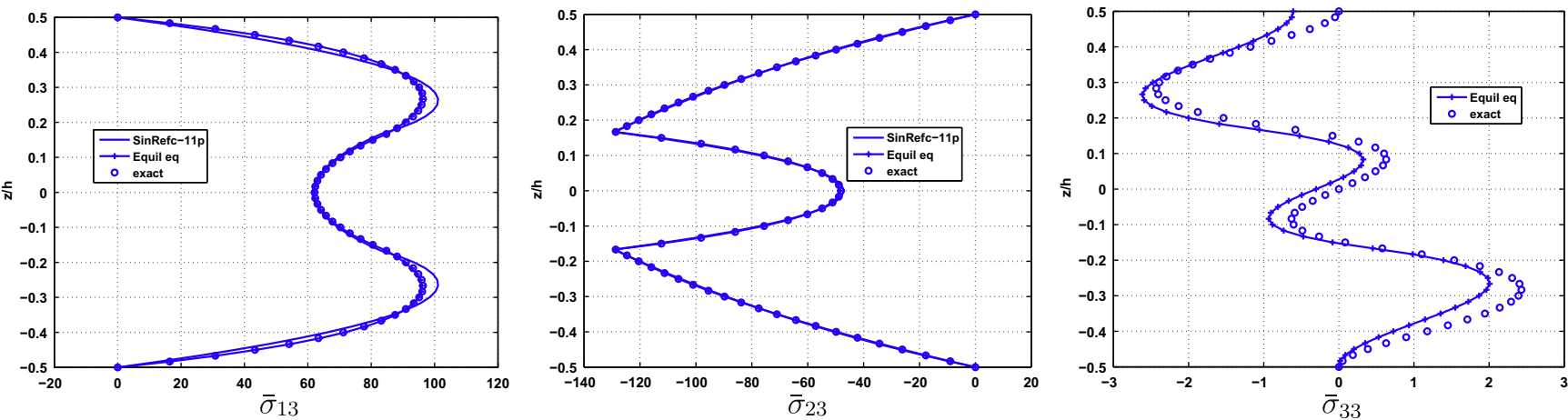

Fig. 18. Distribution of $\bar{\sigma}_{13}$ (left), $\bar{\sigma}_{23}$ (middle) and $\bar{\sigma}_{33}$ (right) along the thickness $-S=4-3$ layers - thermo-mechanical - SinRefc-11p 
The numerical results for deflection, in-plane displacement, shear stresses, and in-plane stresses are given in Tables 9 and 10 for two and three layers, respectively.

It should be noted that the results issued from the SinRefc-11p model are in excellent agreement with the exact solution. The error is less than $3 \%$ regardless of the length-to-thickness ratio for both displacements and stresses, including the transverse shear stresses deduced from the constitutive relation. For $S \leqslant 10$, the maximum error rate becomes lower than $1.7 \%$. Moreover, Figs. $16-18$ show that the distribution of these quantities are similar to the reference solution for the three-layer thick plate. These results show the capability of the model to well represent coupled thermal problems.

\section{Conclusion}

In this paper, a new six-node multilayered triangular finite element has been presented and applied to the analysis of composite laminates and sandwich plates.

This FE is based on an original plate theory involving 11 unknown parameters. The employed sinus theory includes a third-order kinematic per layer for the in-plane displacements and a parabolic distribution of the transverse displacement. The transverse normal stress is introduced in this plate theory. The number of unknowns is independent of the number of layers and all interface and boundary conditions are exactly satisfied. Therefore, this approach has a strong physical meaning.

A conforming FE method is used and high order FE approximations are chosen. The field compatibility for transverse shear strains is assured. It is free of numerical illness such as transverse shear and Poisson lockings, oscillation and spurious mechanics.

The evaluation has been conducted for two- and three-layered plates and a sandwich one under mechanical and thermal loads. The results are in very good agreement with reference solutions. Comparisons with original sinus theory, classical models (FSDT, CLT) and other models available in open literature (ESL and LW) are also given.

In this first attempt to develop a robust and efficient FE for the refined sinus theory, several features have been highlighted: (i) it allows to calculate the transverse shear stresses directly by the constitutive relation with a good accuracy, (ii) it entails a very good compromise between cost and accuracy for displacements and stresses (a mesh with only 2 FE gives the converged value of the transverse displacement), and (iii) by virtue of the new refined kinematics, this FE can be applied to thin to very thick plates under mechanical and thermal loads.

Future works will be focused on shell finite element developments of this refined theory.

\section{Appendix A. Relation between the generalized displacements}

Using the notations introduced in Eqs. (4) and (6), the conditions (8)-(11) can be written under the following form:

$$
\begin{aligned}
{[A]\{v\}=} & \left\{b_{1}\right\} u_{31}^{1}\left(x_{1}, x_{2}\right)+\left\{c_{1}\right\}\left(\theta_{2}\left(x_{1}, x_{2}\right)+w_{0,1}\left(x_{1}, x_{2}\right)\right) \\
& +\left\{d_{1}\right\}\left(u_{1}\left(x_{1}, x_{2}\right)+w_{0,1}\left(x_{1}, x_{2}\right)\right)+\left\{e_{1}\right\} w_{1,1}\left(x_{1}, x_{2}\right) \\
& +\left\{f_{1}\right\} w_{2,1}\left(x_{1}, x_{2}\right)+\left\{b_{2}\right\} v_{31}^{1}\left(x_{1}, x_{2}\right)+\left\{c_{2}\right\} \\
& \times\left(w_{0,2}\left(x_{1}, x_{2}\right)-\theta_{1}\left(x_{1}, x_{2}\right)\right)+\left\{d_{2}\right\}\left(v_{1}\left(x_{1}, x_{2}\right)\right. \\
& \left.+w_{0,2}\left(x_{1}, x_{2}\right)\right)+\left\{e_{2}\right\} w_{1,2}\left(x_{1}, x_{2}\right)+\left\{f_{2}\right\} w_{2,2}\left(x_{1}, x_{2}\right),
\end{aligned}
$$

where $[A]$ is a $(6 * N C-2) \times(6 * N C-2)$ matrix,

$$
\{v\}^{T}=\left\{u_{32}^{1} u_{33}^{1} \cdots u_{31}^{j} u_{32}^{j} u_{33}^{j} \cdots u_{31}^{N C} u_{32}^{N C} u_{33}^{N C} v_{32}^{1} v_{33}^{1} \cdots v_{31}^{j} v_{32}^{j} v_{33}^{j} \cdots\right.
$$
$\left.v_{31}^{N C} v_{32}^{N C} v_{33}^{N C}\right\}^{T}$, and $\left\{b_{\alpha}\right\},\left\{c_{\alpha}\right\},\left\{d_{\alpha}\right\},\left\{e_{\alpha}\right\},\left\{f_{\alpha}\right\}$ are vectors with $(6 * N C-2)$ components.
From the resolution of this linear system, relations between $u_{31}^{j}(j \neq 1), u_{32}^{j}, u_{33}^{j}, v_{31}^{j}(j \neq 1), v_{32}^{j}, v_{33}^{j}, j=1, \ldots, N C$ and the other generalized unknowns can be deduced for a cross-ply composite plate. This relation can be written under the following form:

$$
\left\{\begin{array}{c}
u_{3 i}^{j}\left(x_{1}, x_{2}\right)=\beta_{u i}^{j}\left(\theta_{2}\left(x_{1}, x_{2}\right)+w_{0,1}\left(x_{1}, x_{2}\right)\right)+\eta_{u i}^{j}\left(u_{1}\left(x_{1}, x_{2}\right)+w_{0,1}\left(x_{1}, x_{2}\right)\right) \\
+\delta_{u i}^{j} u_{31}^{1}\left(x_{1}\right)+\lambda_{u i}^{j} w_{1,1}\left(x_{1}, x_{2}\right)+\mu_{u i}^{j} w_{2,1}\left(x_{1}, x_{2}\right) \\
v_{3 i}^{j}\left(x_{1}, x_{2}\right)=\beta_{v i}^{j}\left(w_{0,2}\left(x_{1}, x_{2}\right)-\theta_{1}\left(x_{1}, x_{2}\right)\right)+\eta_{v i}^{j}\left(v_{1}\left(x_{1}, x_{2}\right)+w_{0,2}\left(x_{1}, x_{2}\right)\right) \\
+\delta_{v i}^{j} v_{31}^{1}\left(x_{1}\right)+\lambda_{v i}^{j} w_{1,2}\left(x_{1}, x_{2}\right)+\mu_{v i}^{j} w_{2,2}\left(x_{1}, x_{2}\right), j=1, \ldots, N C \\
i=1,2,3 \\
\text { with } \delta_{\times 1}^{1}=1, \quad \beta_{\times 1}^{1}=\eta_{\times 1}^{1}=\lambda_{\times 1}^{1}=\mu_{\times 1}^{1}=0,
\end{array}\right.
$$

where $\beta_{\times i}^{j}, \delta_{\times i}^{j}, \lambda_{\times i}^{j}, \mu_{\times i}^{j}$, and $\eta_{\times i}^{j}(i=1,2,3, \times=\{u, v\})$ are the coefficients deduced from Eq. (A.1). Note that the expressions of $u_{3 i}^{j}$ and $v_{3 i}^{j}$ are coupled for an angle-ply structure.

Finally, the 11 unknowns become $u_{0}, v_{0}, w_{0}, \theta_{1}, \theta_{2}, u_{1}, v_{1}$, $w_{1}, w_{2}, u_{31}^{1}$ and $v_{31}^{1}$.

In Eqs. (13) and (14), a matrix notation is introduced for the displacement and the strain. In these equations, $\left[F_{u}(z)\right]$ depends on the normal coordinate $z$ according to

$$
\begin{aligned}
{\left[F_{u}(z)\right]=} & {\left[\begin{array}{cccccccccc}
1 & 0 & 0 & F_{u 4}(z) & 0 & 0 & F_{u 7}(z) & F_{u 8}(z) & 0 & \ldots \\
0 & 1 & 0 & 0 & F_{v 5}(z) & F_{v 6}(z) & 0 & 0 & F_{v 9}(z) & \ldots \\
0 & 0 & 1 & 0 & 0 & 0 & 0 & 0 & 0 & \ldots \\
& 0 & F_{u 11}(z) & 0 & 0 & F_{u 14}(z) & 0 & F_{u 16}(z) & 0 \\
0 & 0 & F_{v 12}(z) & 0 & 0 & F_{v 15}(z) & 0 & F_{v 17}(z) \\
z & 0 & 0 & z^{2} & 0 & 0 & 0 & 0
\end{array}\right], }
\end{aligned}
$$

where

$$
\begin{aligned}
& F_{u 4}(z)=f(z)+S_{u \beta}(z)+S_{u \eta}(z) \quad F_{v 5}(z)=f(z)+S_{v \beta}(z)+S_{v \eta}(z) \\
& F_{u 7}(z)=f(z)+S_{u \beta}(z) \quad F_{v 6}(z)=-f(z)-S_{v \beta}(z) \\
& F_{u 8}(z)=z+S_{u \eta}(z) \quad F_{v 9}(z)=z+S_{v \eta}(z) \\
& F_{u 11}(z)=S_{u \lambda}(z) \quad F_{v 12}(z)=S_{v \lambda}(z) \\
& F_{u 14}(z)=S_{u \mu}(z) \quad F_{v 15}(z)=S_{v \mu}(z) \\
& F_{u 16}(z)=S_{u \delta}(z) \quad F_{v 17}(z)=S_{v \delta}(z)
\end{aligned}
$$

and

$\left.\left.S_{\square \times}(z)=\sum_{k=1}^{N C}\left(\zeta_{k} \times_{\square 1}^{k}+-\frac{1}{2}+\frac{3 \zeta_{k}^{2}}{2}\right) \times_{\square 2}^{k}+-\frac{3 \zeta_{k}}{2}+\frac{5 \zeta_{k}^{3}}{2}\right) \times{ }_{\square 3}^{k}\right) \Delta H(k, k+1)$

with $\square=\{u, v\}, \times=\{\beta, \delta, \eta, \lambda, \mu\} \quad$ and $\quad \Delta H(k, k+1)=$ $H\left(z-z_{k}\right)-H\left(z-z_{k+1}\right)$.

\section{References}

[1] J. Reddy, A simple higher-order theory for laminated composite plates, J. Appl. Mech. ASME 51 (4) (1984) 745-752.

[2] H. Murakami, Laminated composite plate theory with improved in-plane responses, J. Appl. Mech. ASME 53 (1986) 661-666.

[3] N. Pagano, Exact solutions for composite laminates in cylindrical bending, J. Compos. Mater. 3 (1969) 398-411.

[4] J. Reddy, On refined computational models of composite laminates, Int. J. Numer. Methods Engrg. 27 (1989) 361-382.

[5] J. Reddy, Mechanics of Laminated Composite Plates and Shells - Theory and Analysis, Springer, 2004.

[6] R. Kapania, S. Raciti, Recent advances in analysis of laminated beams and plates. Part I: Shear effects and buckling, AIAA J. 27 (1989) 923-934.

[7] A. Noor, W. Burton, Assessment of computational models for multilayered composite shells, Appl. Mech. Rev. 43 (4) (1990) 67-97.

[8] E. Carrera, Theories and finite elements for multilayered, anisotropic, composite plates and shells, Arch. Comput. Methods Engrg. 9 (2002) 87-140.

[9] J. Reddy, R. Arciniega, Shear deformation plate and shell theories: from Stavsky to present, Mech. Adv. Mater. Struct. 11 (2004) 535-582.

[10] Y. Zhang, C. Yang, Recent developments in finite elements analysis for laminated composite plates, Compos. Struct. 88 (2009) 147-157. 
[11] P. Gaudenzi, R. Barboni, A. Mannini, A finite element evaluation of single-layer and multi-layer theories for the analysis of laminated plates, Compos. Struct. 30 (1995) 427-440.

[12] R. Chaudhuri, P. Seide, Interlaminar shear stresses around an internal partthrough hole in a stretched laminated composite plate, Compos. Struct. 92 (2010) 835-843.

[13] P. Raghuram, A. Murty, A high precision coupled bending-extension triangular finite element for laminated plates, Comput. Struct. 72 (1999) 763-777.

[14] A. Sheikh, A. Chakrabarti, A new plate bending element based on higher-order shear deformation theory for the analysis of composite plates, Int. J. Solids Struct. 39 (2003) 883-903.

[15] M. Das, A. Barut, E. Madenci, D. Ambur, Complete stress field in sandwich panels with a new triangular finite element of single-layer theory, Comput. Methods Appl. Mech. Engrg. 194 (2005) 2969-3005.

[16] C. Thai, L. Tran, D. Tran, T. Nguyen-Thoi, H. Nguyen-Xuan, Analysis of laminated composite plates using higher-order shear deformation plate theory and node-based smoothed discrete shear gap method, Appl. Math. Model. 36 (2012) 5657-5677.

[17] M. Di Sciuva, A third order triangular multilayered plate finite element with continuous interlaminar stresses, Int. J. Numer. Methods Engrg. 38 (1995) 1 26.

[18] J. Oh, M. Cho, A finite element based on cubic zig-zag plate theory for the prediction of thermo-electric-mechanical behaviors, Int. J. Solids Struct. 41 (2004) 1357-1375.

[19] W. Zhen, C. Wanji, Refined global-local higher-order theory and finite element for laminated plates, Int. J. Numer. Methods Engrg. 69 (2007) 1627-1670.

[20] P. Vidal, O. Polit, A refined sine-based finite element with transverse normal deformation for the analysis of laminated beams under thermomechanica loads, J. Mech. Mater. Struct. 4 (6) (2009) 1127-1155.

21] O. Polit, M. Touratier, High order triangular sandwich plate finite element for linear and nonlinear analyses, Comput. Methods Appl. Mech. Engrg. 185 (2000) 305-324.

[22] N. Pagano, Exact solutions for rectangular bidirectional composites and sandwich plates, J. Comput. Mater. 4 (1970) 20-34.

[23] K. Bhaskar, T. Varadan, J. Ali, Thermoelastic solutions for orthotropic and anisotropic composite laminates, Compos. Part B: Engrg. J. 27B (1996) 415420.

[24] M. Touratier, An efficient standard plate theory, Int. J. Engrg. Sci. 29 (1991) 901-916.

[25] F. Dau, O. Polit, M. Touratier, C1 plate and shell finite elements for geometrically nonlinear analysis of multilayered structures, Comput. Struct. 84 (2006) 1264-1274.
[26] M. Touratier, A generalization of shear deformation theories for axisymmetric multilayered shells, Int. J. Solids Struct. 29 (1992) 1379-1399.

[27] P. Vidal, O. Polit, A thermomechanical finite element for the analysis of rectangular laminated beams, Finite Elem. Anal. Des. 42 (10) (2006) 868-883.

[28] X. Li, D. Liu, Generalized laminate theories based on double superposition hypothesis, Int. J. Numer. Methods Engrg. 40 (1997) 1197-1212.

[29] P. Vidal, O. Polit, A family of sinus finite elements for the analysis of rectangular laminated beams, Compos. Struct. 84 (2008) 56-72, http:// dx.doi.org/10.1016/j.compstruct.2007.06.009

[30] E. Carrera, S. Brischetto, Analysis of thickness locking in classical, refined and mixed multilayered plate theories, Compos. Struct. 82 (2008) 549-562.

[31] S. Cheng, Elasticity theory of plates and a refined theory, J. Appl. Mech. ASME 46 (1979) 644-650.

[32] K. Sze, R. Chen, Y. Cheung, Finite element model with continuous transverse shear stress for composite laminates in cylindrical bending, Finite Elem. Anal Des. 31 (1998) 153-164.

[33] O. Polit, M. Touratier, P. Lory, A new eight-node quadrilateral shear-bending plate finite element, Int. J. Numer. Methods Engrg. 37 (1994) 387-411.

[34] J. Argyris, I. Fried, D. Scharpf, The tuba family of plate elements for the matrix displacement method, Aero. J. Royal Aeronaut. Soc. 72 (1968) 701-709.

[35] H. Ganev, T. Dimitrov, Calculation of arch dams as a shell using an ibm-370 computer and curved finite elements, in: Theory of Shells, North-Holland, Amsterdam, 1980, pp. 691-696.

[36] M. Bernadou, Finite Element Methods for Thin Shell Problems, John Wiley \& Sons, 1996.

[37] D. Dunavant, Hight degree efficient symmetrical gaussian quadrature rules for the triangle, Int. J. Numer. Methods Engrg. 21 (1985) 1129-1148.

[38] O. Polit, M. Touratier, A multilayered/sandwich triangular finite element applied to linear and nonlinear analysis, Compos. Struct. 58 (2002) 121-128.

[39] E. Carrera, Developments, ideas and evaluations based upon the Reissner's mixed theorem in the modeling of multilayered plates and shells, Appl. Mech. Rev. 54 (2001) 301-329.

[40] E. Carrera, Historical review of zig-zag theories for multilayered plates and shells, Appl. Mech. Rev. 56 (3) (2003) 287-308.

[41] M. D'Ottavio, D. Ballhause, T. Wallmersperger, B. Kröplin, Considerations on higher-order finite elements for multilayered plates based on a unified formulation, Comput. Struct. 84 (2006) 1222-1235.

[42] O. Polit, P. Vidal, M. D’Ottavio, Robust c0 high-order plate finite element for thin to very thick structures: mechanical and thermo-mechanical analysis, Int. J. Numer. Methods Engrg. 40 (2012) 429-451, http://dx.doi.org/10.1002/ nme.3328. 